\title{
Evaluation of the Hydraulic
} Performance and Mass Transfer Efficiency of the CSSX Process with the Optimized Solvent in a Single Stage of 5.5-Cm Diameter Centrifugal Contactor

\author{
J. D. Law \\ R. D. Tillotson \\ T. A. Todd
}

September 2002

Idaho National Engineering and Environmental Laboratory Bechtel BWXT Idaho, LLC 


\section{DISCLAIMER}

This information was prepared as an account of work sponsored by an agency of the U.S. Government. Neither the U.S. Government nor any agency thereof, nor any of their employees, makes any warranty, express or implied, or assumes any legal liability or responsibility for the accuracy, completeness, or usefulness of any information, apparatus, product, or process disclosed, or represents that its use would not infringe privately owned rights. References herein to any specific commercial product, process, or service by trade name, trademark, manufacturer, or otherwise, does not necessarily constitute or imply its endorsement, recommendation, or favoring by the U.S. Government or any agency thereof. The views and opinions of authors expressed herein do not necessarily state or reflect those of the U.S. Government or any agency thereof. 


\title{
Evaluation of the Hydraulic Performance and Mass Transfer Efficiency of the CSSX Process with the Optimized Solvent in a Single Stage of $5.5-\mathrm{Cm}$ Diameter Centrifugal Contactor
}

\author{
Jack D. Law \\ Rich D. Tillotson \\ Terry A. Todd \\ September 2002 \\ Idaho National Engineering and Environmental Laboratory \\ Environmental Research and Development Laboratory \\ Idaho Falls, Idaho 83415
}

Prepared for the

U.S. Department of Energy

Assistant Secretary for Environmental Management

Under DOE Idaho Operations Office

Contract DE-AC07-99ID13727 


\begin{abstract}
The Caustic-Side Solvent Extraction (CSSX) process has been selected for the separation of cesium from Savannah River Site high-level waste. The solvent composition used in the CSSX process was recently optimized so that the solvent is no longer supersaturated with respect to the calixarene crown ether extractant. Hydraulic performance and mass transfer efficiency testing of a single stage of 5.5-cm ORNL-designed centrifugal contactor has been performed for the CSSX process with the optimized solvent. Maximum throughputs of the $5.5-\mathrm{cm}$ centrifugal contactor, as a function of contactor rotor speed, have been measured for the extraction, scrub, strip, and wash sections of the CSSX flowsheet at the baseline organic/aqueous flow ratios $(\mathrm{O} / \mathrm{A})$ of the process, as well as at $\mathrm{O} / \mathrm{A}$ 's $20 \%$ higher and $20 \%$ lower than the baseline. Maximum throughputs are comparable to the design throughput of the contactor, as well as with throughputs obtained previously in a 5-cm centrifugal contactor with the non-optimized CSSX solvent formulation. The $20 \%$ variation in $\mathrm{O} / \mathrm{A}$ had minimal effect on contactor throughput. Additionally, mass transfer efficiencies have been determined for the extraction and strip sections of the flowsheet. Efficiencies were lower than the process goal of $\geq 80 \%$, ranging from 72 to $75 \%$ for the extraction section and from 36 to $60 \%$ in the strip section. Increasing the mixing intensity and/or the solution level in the mixing zone of the centrifugal contactor (residence time) could potentially increase efficiencies. Several methods are available to accomplish this including (1) increasing the size of the opening in the bottom of the rotor, resulting in a contactor which is partially pumping instead of fully pumping, (2) decreasing the number of vanes in the contactor, (3) increasing the vane height, or (4) adding vanes on the rotor and baffles on the housing of the contactor. The low efficiency results obtained stress the importance of proper design of a centrifugal contactor for use in the CSSX process. A prototype of any centrifugal contactors designed for future pilot-scale or full-scale processing should be thoroughly tested prior to implementation.
\end{abstract}




\section{ACKNOWLEDGEMENTS}

This work was supported by the U. S. Department of Energy, Office of Environmental Management, through the Tanks Focus Area of the Office of Science and Technology.

The authors wish to thank Tim Bronson of the INTEC Quality Control Laboratory for his assistance in solution and simulant makeup and Earlen Wade for his support in contactor setup, modification, and testing. Also, Peter Bonnesen of ORNL for providing the CSSX solvent for this testing and Ralph Leonard of ANL for his assistance in modeling of the centrifugal contactor and analysis of the data. 


\section{CONTENTS}

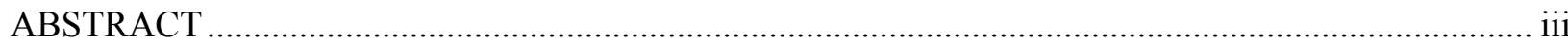

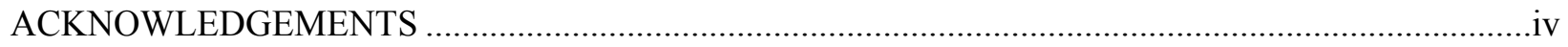

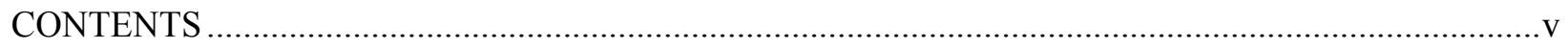

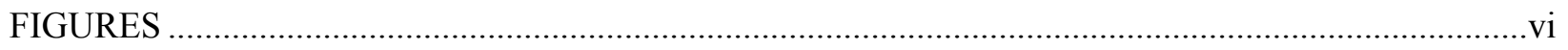

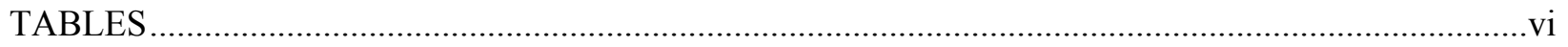

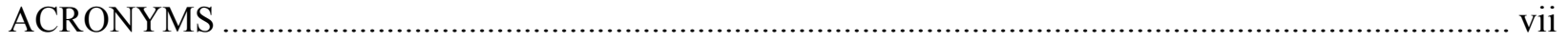

INTRODUCTION

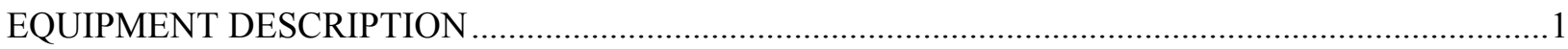

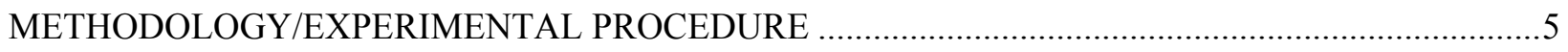

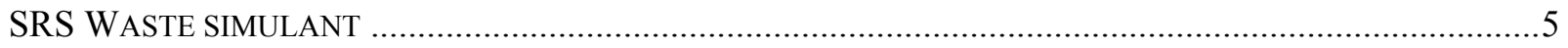

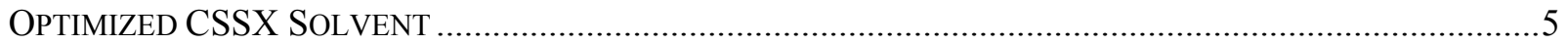

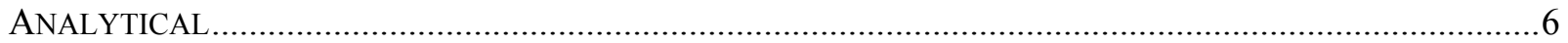

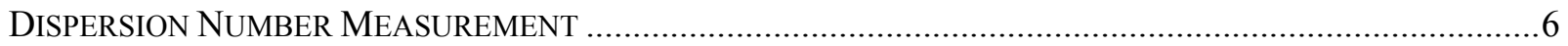

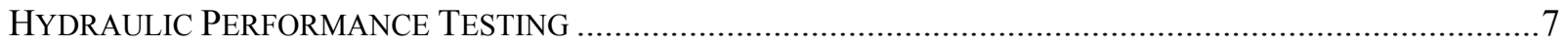

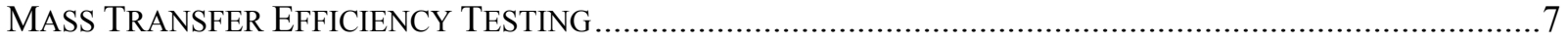

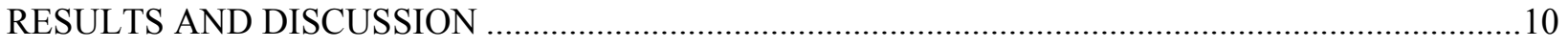

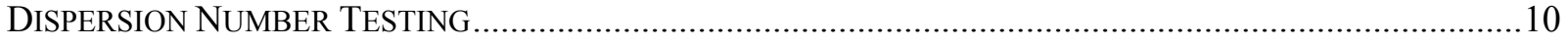

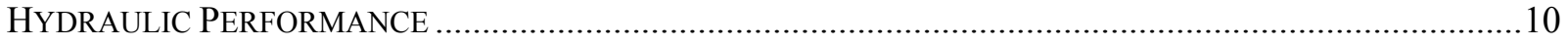

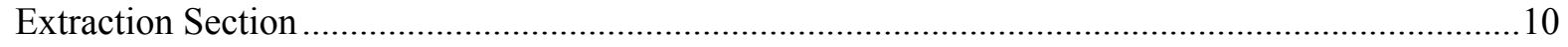

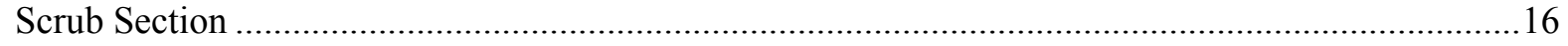

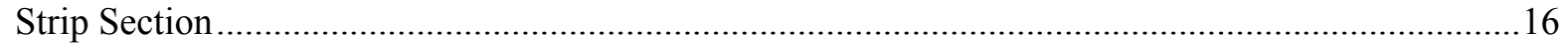

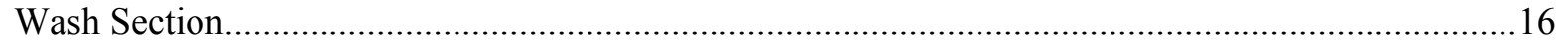

Comparison of Maximum Throughput to Previous Results with Non-Optimized Solvent .................17

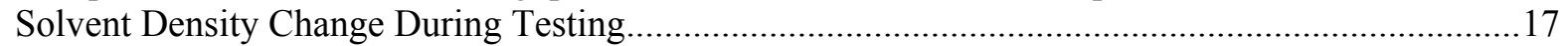

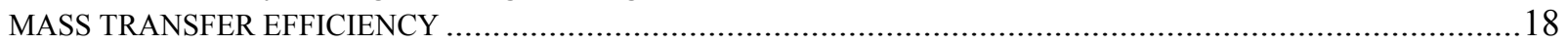

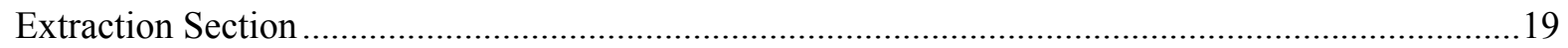

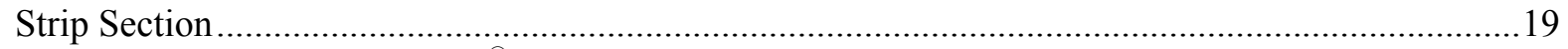

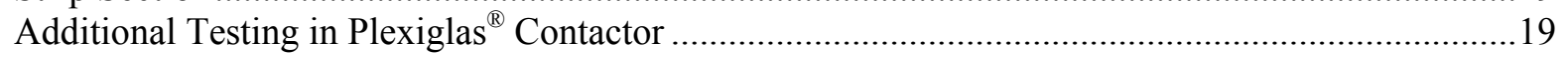

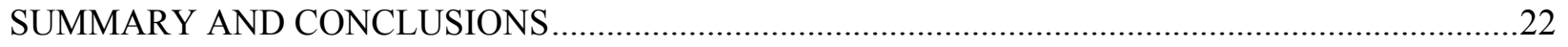

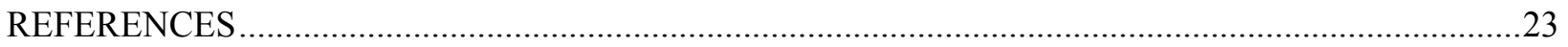




\section{FIGURES}

1. Experimental setup for contactor hydraulic and mass transfer efficiency tests............................... 3

2. $\quad 5.5-\mathrm{cm}$ diameter centrifugal contactor test setup ....................................................................

3. 5.5-cm centrifugal contactor "four-pack" configured for testing of a single stage ......................... 4

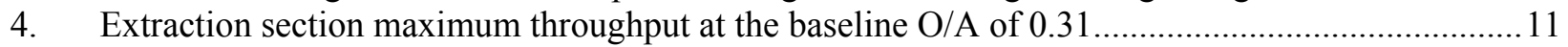

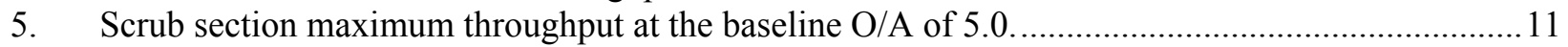

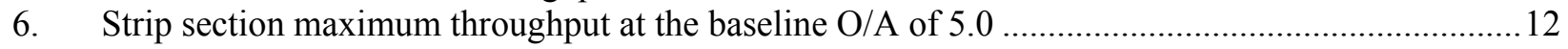

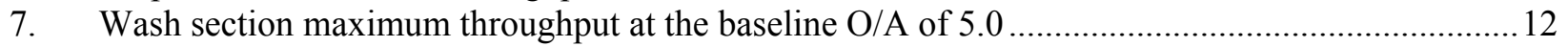

8. Extraction section maximum throughput as a function of $\mathrm{O} / \mathrm{A}$ ratio $(\geq 1 \%$ entrainment) ...............13

9. Scrub section maximum throughput as a function of $\mathrm{O} / \mathrm{A}$ ratio $(\geq 1 \%$ entrainment $) \ldots . . . . . . . . . . . . . . . . . .13$

10. Strip section maximum throughput as a function of $\mathrm{O} / \mathrm{A}$ ratio $(\geq 1 \%$ entrainment) ....................... 14

11. Wash section maximum throughput as a function of $\mathrm{O} / \mathrm{A}$ ratio $(\geq 1 \%$ entrainment $)$..................... 14

12. Comparison of extraction section maximum throughput with previous results using the nonoptimized solvent.

13. Comparison of strip section maximum throughput with previous results using the non-optimized

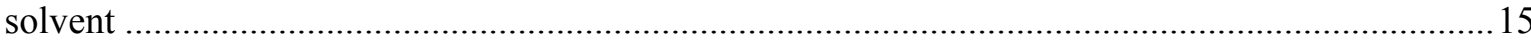

14. Comparison of total maximum throughput in the extraction section with previous results obtained

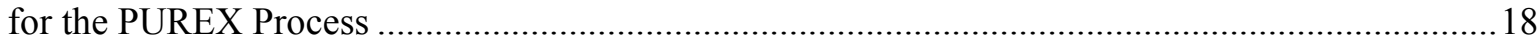

15. Single stage 5.5-cm centrifugal contactor with Plexiglas ${ }^{\circledR}$ housing ...........................................20

\section{TABLES}

1. Specifications of the ORNL-designed 5.5 -cm diameter centrifugal contactor..................................2

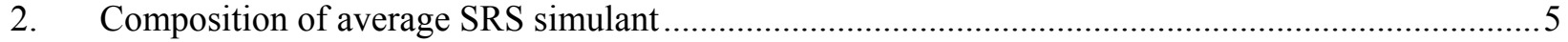

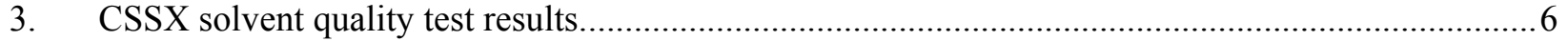

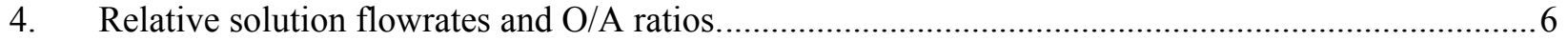

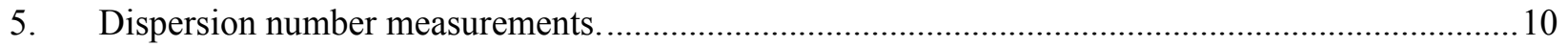

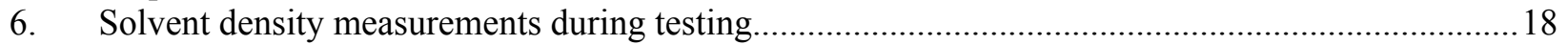

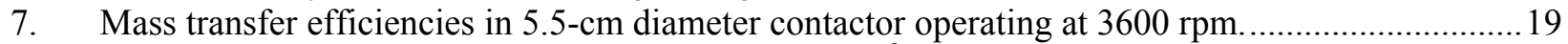

8. Mass transfer efficiencies using single stage Plexiglas ${ }^{\circledR} 5.5-\mathrm{cm}$ diameter contactor ......................21 


\section{ACRONYMS}

$\begin{array}{ll}\text { ANL } & \text { Argonne National Laboratory } \\ \text { BOBCalixC6 } & \text { Calix[4]arene-bis(tert-octylbenzo-crown-6) } \\ \text { CINC } & \text { Costner Industries Nevada Corp. } \\ \text { Cs-7SB } & \text { 1-(2,2,3,3,-tetrafluoropropoxy)-3-(4-sec-butylphenoxy)-2-propanol } \\ \text { CSSX } & \text { Caustic-Side Solvent Extraction } \\ \text { INEEL } & \text { Idaho National Engineering and Environmental Laboratory } \\ \text { ORNL } & \text { Oak Ridge National Laboratory } \\ \text { SRS } & \text { Savannah River Site } \\ \text { SRTC } & \text { Savannah River Technology Center } \\ \text { TOA } & \text { Trioctylamine }\end{array}$




\section{Evaluation of the Hydraulic Performance and Mass Transfer Efficiency of the CSSX Process with the Optimized Solvent in a Single Stage of $5.5-\mathrm{Cm}$ Diameter Centrifugal Contactor}

\section{INTRODUCTION}

There are 34 million gallons of high-level waste requiring treatment at the Savannah River Site (SRS). As a part of this treatment process, the cesium will be removed from the waste, then vitrified for disposal. After the cesium is removed, the decontaminated solution will be immobilized as a low-level grout. The Caustic-Side Solvent Extraction (CSSX) process has been selected by the Department of Energy as the preferred alternative for cesium removal at the SRS.

The CSSX process was developed at Oak Ridge National Laboratory (ORNL) as a method to remove cesium from alkaline solutions such as DOE tank wastes at the SRS and Hanford, WA (Bonnesen et al. 1998). The CSSX solvent consists of (1) calix[4]arene-bis(tert-octylbenzo-crown-6), designated BOBCalixC6, for the extraction of cesium, (2) a modifier, 1-(2,2,3,3,-tetrafluoropropoxy)-3-(4-secbutylphenoxy)-2-propanol (Cs-7SB), to keep the extractant dissolved in the solvent and increase the ability to extract cesium in the extraction section, (3) trioctylamine (TOA), to suppress the effects from organic impurities so that the cesium can be back extracted from the solvent in the strip section, and (4) an Isopar ${ }^{\circledR} \mathrm{L}$ diluent. In earlier development and testing of the CSSX process, the solvent composition was $0.01 \underline{\mathrm{M}}$ BOBCalixC6, $0.50 \underline{\mathrm{M}} \mathrm{Cs}-7 \mathrm{SB}$, and $0.001 \underline{\mathrm{M}}$ TOA in Isopar ${ }^{\circledR} \mathrm{L}$. Recently, the composition of the CSSX solvent has been optimized to $0.007 \underline{\mathrm{M}}$ BOBCalixC6, 0.75 $\underline{\mathrm{M}} \mathrm{Cs}-7 \mathrm{SB}$, and $0.003 \underline{\mathrm{M}} \mathrm{TOA}$ in Isopar $^{\mathbb{B}} \mathrm{L}$ (Klatt et al. 2002). With this change in composition, the CSSX solvent is no longer supersaturated with respect to the BOBCalixC6. The optimized solvent also has added resistance to thirdphase formation at lower plant operating temperatures and to organic impurities that could limit back extraction of the cesium from the solvent. The density of the optimized solvent at $25^{\circ} \mathrm{C}$ increased from 810 to $852 \mathrm{~g} / \mathrm{L}$ and the viscosity at $25^{\circ} \mathrm{C}$ increased from approximately 2.7 centipoise to 3.5 centipoise.

Testing was performed, prior to optimization of the CSSX solvent composition, to evaluate the hydraulic performance and mass transfer efficiency for the CSSX process in a 5-cm diameter centrifugal contactor (Birdwell and Anderson 2001). Since the optimized solvent has different physical properties than the previous solvent, the hydraulic performance of a centrifugal contactor may be affected. This created a need for additional hydraulic and mass transfer efficiency testing to be performed for the CSSX process using the optimized solvent.

Hydraulic and mass transfer efficiency testing for the CSSX process has been performed at the Idaho National Engineering and Environmental Laboratory (INEEL) using the optimized solvent and a single stage of 5.5-cm diameter centrifugal contactor. This testing consisted of (1) measurement of dispersion numbers for each of the flowsheet sections, (2) determination of the maximum throughput for the $5.5-\mathrm{cm}$ contactor in each of the flowsheet sections, and (3) determination of the mass transfer efficiency of cesium in the extraction and strip sections. Results from this testing are presented in this report and compared to results obtained at ORNL with the prior solvent formulation.

\section{EQUIPMENT DESCRIPTION}

Measurement of dispersion numbers for each of the flowsheet sections was performed using standard laboratory glassware $(100-\mathrm{mL}$ graduated cylinders) and a stopwatch. 
Hydraulic and mass transfer efficiency testing was performed using a single stage of an ORNLdesigned 5.5-cm diameter centrifugal contactor four-pack. Table 1 lists the specifications of the contactor. The equipment is located in Lab 117 of building INTEC 637. A diagram of the experimental setup is shown in Figure 1 and photographs of the centrifugal contactor and experimental setup are shown in Figures 2 and 3. The speed of the centrifugal contactor was controlled from 0 to 4,400 rpm with a DC motor controller and verified during testing with a calibrated digital tachometer. Ten-liter Teflon ${ }^{\circledR}$ feed and product vessels were used for the solvent and ten-gallon high density polyethylene vessels were used for the aqueous solutions. All feed and product lines consisted of Teflon ${ }^{\circledR}$-lined Tygon ${ }^{\circledR}$ tubing. Solution was pumped from the feed containers to the contactor stage using piston-type metering pumps (Fluid Metering Inc.). The solvent feed pump, model Q2V with dual pump heads Q2, has a maximum capacity of $2600 \mathrm{~mL} / \mathrm{min}$. Each pump head consisted of a stainless steel cylinder case, ceramic piston, and a ceramic cylinder liner. The aqueous feed pump, model Q2V with dual pump heads Q3, has a maximum capacity of $4600 \mathrm{~mL} / \mathrm{min}$. Each pump head consisted of a fluorocarbon (PVDF) cylinder case, ceramic piston, and a ceramic cylinder liner. Flow rates were adjusted by controlling pump speed using a ten-turn potentiometer or by manual adjustment of the piston stroke length and/or a combination of the two. Aqueous and organic solution exited the contactor stage and drained either to a receiver vessel (mass transfer efficiency tests) or back to the feed vessel (hydraulic performance tests). A tee in the drain lines with ball valves on the outlets provided a method for sampling the effluent streams. A thermocouple probe was inserted through the contactor drain line to a point just below the contactor mixing zone so that solution temperature inside the contactor stage could be monitored during operation.

Re-equilibration of the aqueous and organic samples from the mass transfer efficiency testing was accomplished using standard laboratory equipment and a temperature controlled water bath with a calibrated thermocouple. Temperatures of the solutions were maintained within the accuracy of the calibrated thermocouple $\left( \pm 0.1^{\circ} \mathrm{C}\right)$.

It should be noted that all glassware, plasticware, and solution vessels used for solution makeup or testing, as well as all wetted parts of the centrifugal contactor setup, were rinsed per the following procedure as recommended by ORNL.

1) Rinse 3 times with demineralized water

2) Rinse 3 times with ethanol

3) Rinse 3 times with acetone

4) Dry using an inert gas such as argon or nitrogen

Table 1. Specifications of the ORNL-designed $5.5-\mathrm{cm}$ diameter centrifugal contactor.

\begin{tabular}{ll}
\hline Specification & Dimension \\
\hline Rotor diameter & $5.5 \mathrm{~cm}$ \\
Aqueous weir radius & $12.70 \mathrm{~mm}$ \\
Organic weir radius & $10.44 \mathrm{~mm}$ \\
Rotor inlet radius & $7.89 \mathrm{~mm}$ \\
Aqueous underflow radius & $22.71 \mathrm{~mm}$ \\
Height of separating zone below organic weir & $109.0 \mathrm{~mm}$ \\
Height between weirs & $18.26 \mathrm{~mm}$ \\
Rotor/housing gap & $5.75 \mathrm{~mm}$ \\
Number of vanes below rotor & 8 \\
Inlet and outlet port configuration & Tangential \\
\hline
\end{tabular}




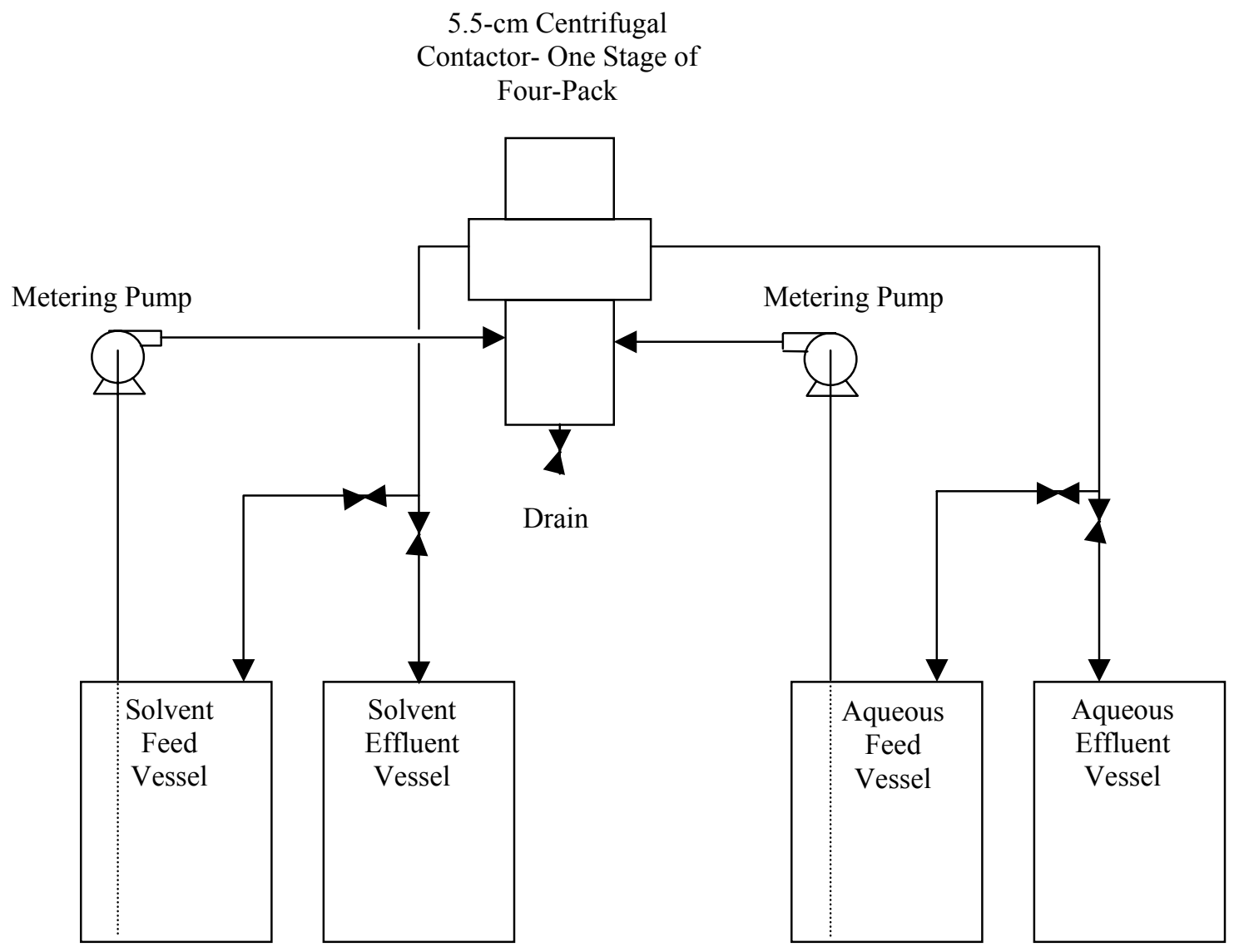

Figure 1. Experimental setup for contactor hydraulic and mass transfer efficiency tests. 


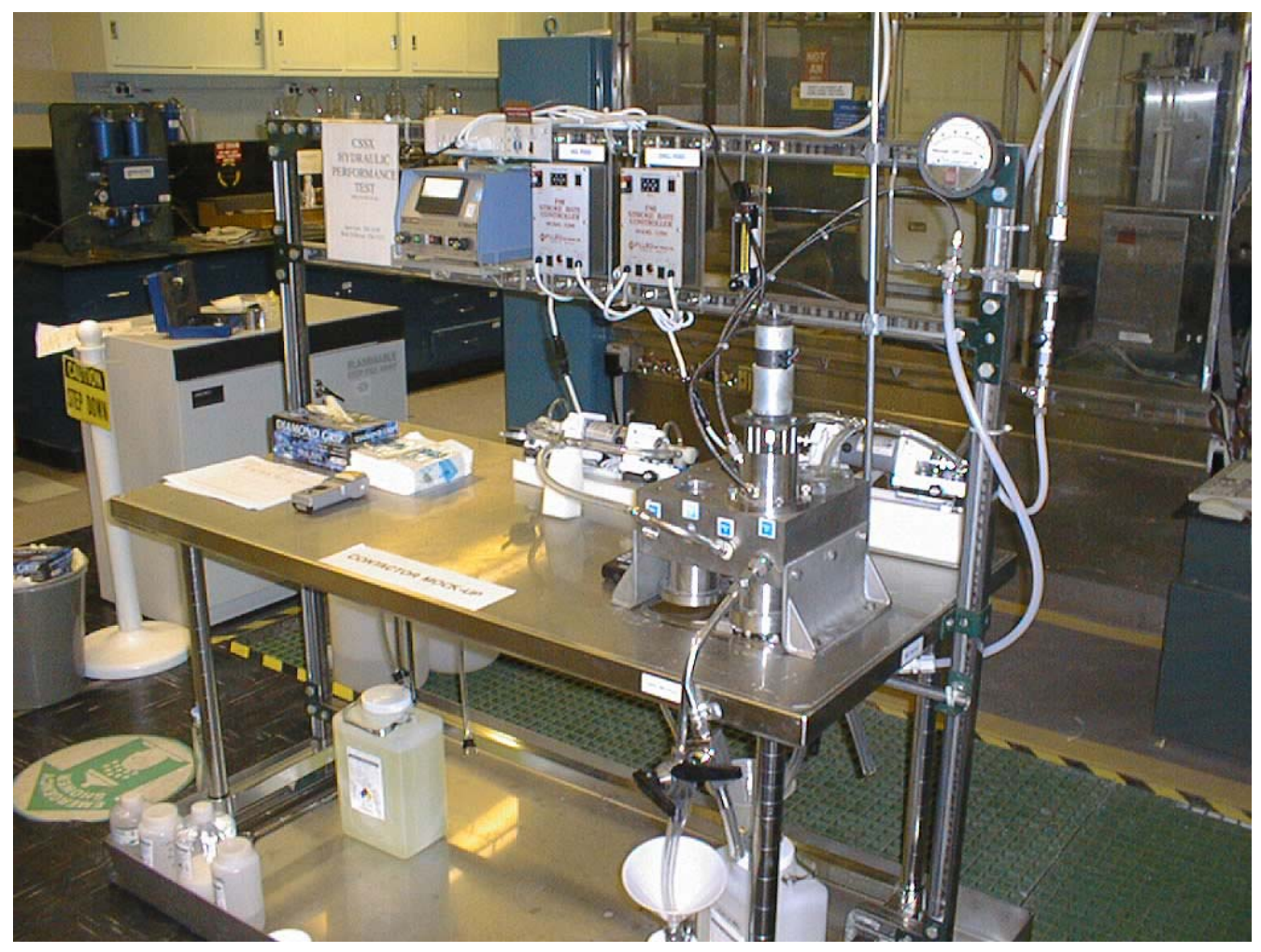

Figure 2. $5.5-\mathrm{cm}$ diameter centrifugal contactor test setup.

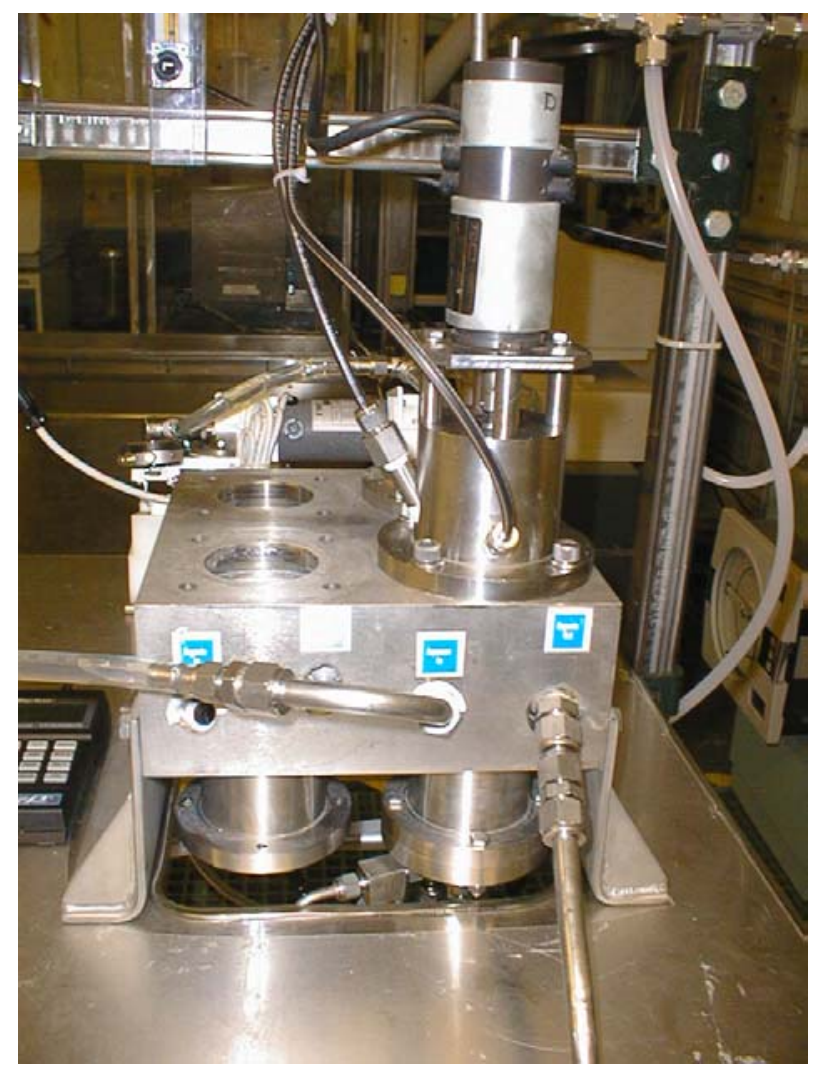

Figure 3. 5.5-cm centrifugal contactor "four-pack" configured for testing of a single stage. 


\section{METHODOLOGYIEXPERIMENTAL PROCEDURE}

\section{SRS Waste Simulant}

SRS waste simulant for use in testing was prepared according to a method developed by SRTC personnel for the preparation of "average" SRS supernate simulant (Peterson 2000). The target composition of the average SRS simulant is given in Table 2. Three batches of simulant were prepared. A 1-liter batch was prepared for use in dispersion number measurements, an 8-liter batch was prepared for use in the hydraulic performance testing, and an 8-liter batch was prepared for use in the mass transfer efficiency testing. All simulants were prepared by the INEEL Quality Control Laboratory.

Table 2. Composition of average SRS simulant.

\begin{tabular}{cccc}
\hline Component & Conc., $\mathrm{mol} / \mathrm{L}$ & Component & Conc., $\mathrm{mg} / \mathrm{L}$ \\
\hline $\mathrm{Na}$ & 5.6 & $\mathrm{Cu}$ & 1.44 \\
$\mathrm{~K}$ & 0.015 & $\mathrm{Cr}$ & 75 \\
$\mathrm{Cs}$ & 0.00014 & $\mathrm{Ru}$ & 0.82 \\
$\mathrm{OH}$ & 2.06 & $\mathrm{Pd}$ & 0.41 \\
$\mathrm{NO}_{3}$ & 2.03 & $\mathrm{Rh}$ & 0.21 \\
$\mathrm{NO}_{2}$ & 0.50 & $\mathrm{Fe}$ & 1.44 \\
$\mathrm{AlO}_{2}$ & 0.28 & $\mathrm{Zn}$ & 8 \\
$\mathrm{CO}_{3}{ }^{2}$ & 0.15 & $\mathrm{Sn}$ & 2.4 \\
$\mathrm{SO}_{4}{ }^{2}$ & 0.14 & $\mathrm{Hg}$ & 0.05 \\
$\mathrm{Cl}$ & 0.024 & $\mathrm{~Pb}$ & 2.1 \\
$\mathrm{~F}$ & 0.028 & Ag & 0.01 \\
$\mathrm{PO}_{4}$ & 0.007 & Tri-n-butyl phosphate (TBP) & 0.5 \\
$\mathrm{C}_{2} \mathrm{O}_{4}$ & 0.008 & Di-n-butyl phosphate (DBP) & 25 \\
$\mathrm{SiO}_{3}$ & 0.03 & Mono-n-butyl phosphate (MBP) & 25 \\
$\mathrm{MoO}_{4}$ & 0.00007 & n-Butanol & 2 \\
$\mathrm{NH}_{3}$ & 0.001 & Formate & 1500 \\
& & Tri-methylamine (TMA) & 10 \\
\hline
\end{tabular}

\section{Optimized CSSX Solvent}

The composition of the optimized CSSX solvent used in all testing was $0.007 \underline{\mathrm{M}}$ BOBCalixC6, 0.75 $\underline{\mathrm{M}} \mathrm{Cs}-7 \mathrm{SB}$, and $0.003 \underline{\mathrm{M}} \mathrm{TOA}$ in Isopar ${ }^{\mathbb{B}} \mathrm{L}$. The solvent was prepared by Peter Bonnesen at ORNL and shipped to the INEEL. Two 5- liter batches of solvent were obtained. Lot $150 \mathrm{~W}$ had a density of $851.8 \pm$ $0.1 \mathrm{~g} / \mathrm{L}$ at $25^{\circ} \mathrm{C}$ as measured at ORNL prior to shipment. This solvent was used as received for measurement of the dispersion number and for all hydraulic performance testing. Lot $190 \mathrm{~W}$ had a density of $851.8 \pm 0.2 \mathrm{~g} / \mathrm{L}$ at $25^{\circ} \mathrm{C}$ as measured at ORNL prior to shipment. This solvent was used as received for mass transfer efficiency testing.

Prior to use, quality control distribution coefficient testing was performed on both batches of CSSX solvent using the procedure provided by ORNL. Results of these tests for Lots $150 \mathrm{~W}$ and $190 \mathrm{~W}$ are presented in Table 3. All of the distribution coefficients were within $15 \%$ of the values measured at ORNL prior to shipment, which was the criterion used for acceptance of the solvent for use. 
Table 3. CSSX solvent quality test results.

\begin{tabular}{cccc}
\hline Contact & $\begin{array}{c}\mathrm{D}_{\mathrm{Cs}} \text { (average of two } \\
\text { measurements) }\end{array}$ & Target $\mathrm{D}_{\mathrm{Cs}}$ & \% of Target \\
\hline Lot 150W-Extraction & 13.6 & 14.09 & 96.5 \\
Lot 150W-Scrub & 1.27 & 1.222 & 103.9 \\
Lot 150W-Strip & 0.0261 & 0.0241 & 108.3 \\
Lot 190W-Extraction & 14.0 & 14.02 & 99.9 \\
Lot 190W-Scrub & 1.32 & 1.168 & 113.0 \\
Lot 190W-Strip & 0.0220 & 0.0195 & 112.8 \\
\hline
\end{tabular}

\section{Analytical}

SRS waste simulant feed samples were submitted for analysis to the INTEC Analytical Laboratory. Aluminum, chromium, copper, iron, molybdenum, lead, palladium, rhodium, ruthenium, silicon, and zinc analyses were performed using Inductively Coupled Plasma Emission Spectroscopy (ICP-ES). Sodium, cesium, and potassium analyses were performed using Atomic Absorption Spectroscopy. Aqueous and organic samples from mass transfer efficiency testing were analyzed by ICP- mass spectroscopy (ICPMS). Solvent samples were digested in nitric acid in a closed vessel microwave digestion system (CEM model MDS-2100 laboratory microwave with CEM lined digestion vessels) prior to analysis.

Additionally, indirect cesium analysis of the solvent samples was performed by stripping the solvent samples several times with dilute nitric acid at an organic to aqueous phase ratio $(\mathrm{O} / \mathrm{A})$ of 0.2 .

\section{Dispersion Number Measurement}

The dispersion number is a measurement of the general ability of a two-phase dispersion to separate (Leonard 1995). A dispersion number greater than 4.4E-04 generally indicates good phase separation in solvent extraction equipment. Dispersion numbers were measured for the extraction, scrub, strip, and sodium hydroxide wash sections of the CSSX flowsheet. Phase volumes proportional to the flow rates of the baseline CSSX flowsheet, as summarized in Table 4, were used for the testing.

Table 4. Relative solution flowrates and $\mathrm{O} / \mathrm{A}$ ratios.

\begin{tabular}{cccc}
\hline Section & Stream & Relative Flow & Organic/Aqueous Ratio \\
\hline Extraction & Solvent Feed & 0.333 & 0.31 \\
& Waste Simulant Feed & 1.00 & \\
Scrub & Scrub Feed & 0.0667 & 5.0 \\
Strip & Strip Feed & 0.0667 & 5.0 \\
Wash & Wash Feed & 0.0667 & 5.0 \\
\hline
\end{tabular}

Measured volumes of aqueous and organic solutions, at a phase volume ratio as shown in Table 4 for the section of the flowsheet being tested, were placed into a graduated cylinder. For determining the dispersion number in the extraction section, aqueous solution consisting of SRS waste simulant mixed

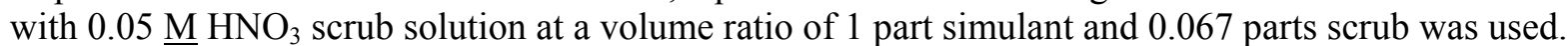
This results in an aqueous solution similar to the extraction section aqueous solution in an operating process where the scrub effluent mixes with the aqueous feed solution. The solution in the graduated cylinder was agitated manually for 20 seconds, agitation was suspended for 10 seconds, and manual agitation was resumed for an additional 20 seconds. The total height of the dispersion and the time required for the dispersion to break were then measured. The criteria used to determine the point at which 
the dispersion broke was when the interface had returned to its original position and droplets were no longer observed at the interface or in the aqueous or organic phases. Dispersion numbers were calculated according to the equation

$$
N_{D i}=\frac{1}{t_{b}} \sqrt{\frac{z}{g_{c}}}
$$

where $\mathrm{t}_{\mathrm{b}}$ is the break time $(\mathrm{s}), \mathrm{z}$ is the dispersion band height $(\mathrm{ft})$, and $\mathrm{g}_{\mathrm{c}}$ is the gravitational constant $\left(32.172 \mathrm{ft} / \mathrm{s}^{2}\right)$. This process was repeated three times for each flowsheet section.

\section{Hydraulic Performance Testing}

The hydraulic performance of a centrifugal contactor is evaluated by measuring the maximum solution throughput (sum of the aqueous and organic flowrates) for which the maximum allowable crossphase entrainment is not exceeded. Cross-phase entrainment is defined as aqueous solution carryover in the organic effluent stream or organic carryover in the aqueous effluent stream. For the purposes of this testing, two criteria for cross-phase entrainment were used: (1) any observable cross-phase entrainment, as observed by aqueous bubbles or a layer in the bottom of the solvent sample or an organic film or layer on the top of the aqueous sample, and (2) measurement of $\geq 1 \%$ cross-phase entrainment.

The maximum throughput was determined for the extraction, scrub, strip and wash sections of the CSSX flowsheet at the baseline O/A ratios, as shown in Table 4, at rotor speeds of 2800 (extraction section only), $3200 \mathrm{rpm}, 3600 \mathrm{rpm}, 4000 \mathrm{rpm}$, and $4400 \mathrm{rpm}$. Additionally, the effect of small changes in aqueous or organic flowrates was evaluated by measuring the maximum throughput at O/A ratios $20 \%$ higher and lower than the baseline O/A's.

Testing was performed with the 5.5 -cm contactor configured for continuous recycle of the aqueous and organic effluents to the feed vessels. The contactor was started at the speed to be tested. After aqueous flow was initiated and observed exiting the contactor stage, the solvent flow was initiated. After a minimum of three minutes of operation, the aqueous and organic effluent streams were sampled and visually examined for cross-phase entrainment. If cross-phase entrainment was $<1 \%$ in both samples, the aqueous and organic feed flowrates were increased incrementally and proportionally. At each new set of flowrates, the samples were examined for cross-phase entrainment after a minimum of three minutes of operation. This process continued until $\geq 1 \%$ cross-phase entrainment was measured in either sample. The flowrates at which cross-phase entrainment was first observed and the flowrates at which entrainment was $\geq 1 \%$ were recorded. Flowrates were reduced proportionally until cross-phase entrainment was no longer observed, the system allowed to stabilize, and the process repeated until $\geq 1 \%$ cross-phase entrainment was measured. This process was repeated for each contactor rotor speed, $\mathrm{O} / \mathrm{A}$ ratio, and flowsheet section tested.

\section{Mass Transfer Efficiency Testing}

Mass transfer efficiency was measured for the extraction and strip section of the CSSX flowsheet using a single stage of $5.5-\mathrm{cm}$ diameter centrifugal contactor. All testing was performed at $3600 \mathrm{rpm}$ and at an $\mathrm{O} / \mathrm{A}$ of 0.31 for the extraction section and 5.0 for the strip section. For the extraction section, testing was performed at $75 \%(1,130 \mathrm{~mL} / \mathrm{min})$ and $37.5 \%(565 \mathrm{~mL} / \mathrm{min})$ of the maximum throughput determined in the hydraulic performance testing. For the strip section, testing was performed at the throughputs corresponding to the throughputs tested for the extraction section based upon the baseline O/A's of the CSSX flowsheet $(321 \mathrm{~mL} / \mathrm{min}$ and $161 \mathrm{~mL} / \mathrm{min})$. 
Testing was performed with the 5.5 -cm centrifugal contactor configured for once through processing of the feed solutions. Aqueous feed solution consisted of the composition of the aqueous phase in the section of the flowsheet being tested (extraction or strip). For the extraction section, the waste simulant was mixed with $0.05 \mathrm{M} \mathrm{HNO}_{3}$ scrub at a volume ratio of 1 part simulant and 0.067 parts scrub. This results in an aqueous solution similar to the extraction section aqueous solution in an operating process where the scrub effluent mixes with the aqueous feed solution. Fresh solvent was used for the extraction section testing and solvent effluent from the extraction section was used for the strip section testing (after performing two scrub contacts of the solvent). The contactor was started at a speed of 3,600 $\mathrm{rpm}$. After aqueous flow was initiated and observed exiting the contactor stage, the solvent flow was initiated. The aqueous and organic effluent streams were sampled 2.5 and 5 minutes after the initiation of solvent flow. These operation times correspond to 14 and 28 residence times for the aqueous solution and 7.5 and 15 residence times for the organic solution, which should be adequate to ensure steady state was reached. In order to determine the mass transfer efficiency at a lower throughput, the solvent and aqueous flowrates were reduced by $50 \%$ and the aqueous and organic effluent streams were sampled 3 and 6 minutes after the reduction of flowrates. These operation times correspond to 7 and 14 residence times for the aqueous solution and 3.2 and 7.5 residence times for the organic solution, which should be adequate to ensure steady state was reached.

This testing was then repeated for the strip section of the CSSX flowsheet. Prior to performing mass transfer efficiency testing of the strip section, the solvent was scrubbed with $0.05 \mathrm{M} \mathrm{HNO}_{3}$. Two contacts were performed using the 5.5-cm contactor stage operating at an O/A of 5.0. Mass transfer efficiency testing was then performed for the strip section. The aqueous and organic effluent streams were sampled 2.5 and 5 minutes after the initiation of solvent flow. These operation times correspond to 1.8 and 3.6 residence times for the aqueous solution and 5 and 10 residence times for the organic solution, which should be adequate to ensure steady state was reached. In order to determine the mass transfer efficiency at a lower throughput, the solvent and aqueous flowrates were reduced by $50 \%$ and the aqueous and organic effluent streams were sampled 3 and 5 minutes after the reduction of flowrates. These operation times correspond to 1.1 and 1.8 residence times for the aqueous solution and 3 and 5 residence times for the organic solution. These residence times are low, indicating steady state conditions may not have been reached. Typically, three residence times of the aqueous and organic phases will ensure steady state conditions are reached. The short residence times are the result of the volume of solvent available from the mass transfer efficiency testing in the extraction section, which limited the operational time.

Temperature of the solution in the centrifugal contactor was monitored during operation of the mass transfer efficiency testing using a thermocouple which was inserted through the drain line of the contactor. Temperature of the solution was recorded at the time each sample was taken.

In order to calculate the stage efficiency of the centrifugal contactor, a portion of the samples from the mass transfer efficiency tests were re-equilibrated. Sealed vials $(50-\mathrm{mL}$ polypropylene centrifuge tubes) containing the aqueous and organic samples were placed in a constant temperature water bath which was set to the temperature at which the samples were originally taken. After equilibrating thermally for at least 15 minutes, aliquots of the samples (at a volume ratio equivalent to the flowrates at which the mass transfer tests were performed) were placed in a clean vial and returned to the water bath. After equilibrating thermally for at least 15 minutes, the vials were agitated for two 20 -second intervals with an intermediate 10 -second hold period. The vials were returned to the water bath and the phases allowed to separate by gravity. After a minimum of 10 minutes of separation, the samples were centrifuged and returned to the water bath for a minimum of 5 minutes. Samples of the aqueous and organic phases were taken and submitted, along with samples of the original aqueous and organic phases (prior to reequilibration), for cesium analysis by ICP mass spectrophotometry. 
Mass transfer efficiency was calculated as follows, based on the aqueous phase compositions.

$$
\eta=\frac{\left(X-X_{i n}\right)}{\left(X_{e q}-X_{i n}\right)} * 100
$$

where $X$ is the cesium concentration of the aqueous effluent, $X_{i n}$ is the inlet aqueous cesium concentration, and $X_{e q}$ is the cesium concentration of the aqueous effluent after re-equilibration. Aqueous phase concentrations were used for calculation of the efficiency due to the slightly larger uncertainty in the solvent sample analyses resulting from the digestion of the solvent.

The following guide was used for flushing the single stage $5.5-\mathrm{cm}$ centrifugal contactor when preparing for hydraulic or mass transfer efficiency testing of a different section (extraction, scrub, strip, wash) of the CSSX flowsheet.

1) Drain the feed lines and pump by operating the feed pumps in the reverse direction.

2) Drain solution from the centrifugal contactor stage through the drain valve located on the bottom of the contactor stage.

3) Flush a minimum of 5 liters of demineralized water through the contactor stage (while operating) as a preliminary flush of the lines and contactor.

4) Remove the contactor rotor assembly and flush/soak all wetted parts of the assembly using the aqueous solution planned for the next phase of testing (e.g. $0.05 \underline{\mathrm{M} \mathrm{HNO}} 3$ scrub solution when switching testing from the extraction to scrub section). Continue flushing until the $\mathrm{pH}$ of the rinsate is the same as the $\mathrm{pH}$ of the rinse solution.

5) Flush all wetted parts of the contactor housing until the $\mathrm{pH}$ of the rinsate is the same as the $\mathrm{pH}$ of the rinse solution. This includes flushing the adjacent contactor housing through which the aqueous phase exits.

6) Flush the drain lines, samplers, and feed/product vessels until the $\mathrm{pH}$ of the rinsate is the same as the $\mathrm{pH}$ of the rinse solution.

7) Flush feed lines and pumps until the $\mathrm{pH}$ of the rinsate is the same as the $\mathrm{pH}$ of the rinse solution. 


\section{RESULTS AND DISCUSSION}

\section{Dispersion Number Testing}

Results of the dispersion number measurements are summarized in Table 5. Dispersion numbers were measured for the extraction, scrub, strip and wash sections of the flowsheet. The dispersion number averaged 1.32E-03 in the extraction section, 6.01E-04 in the scrub section, 8.35E-04 in the strip section, and 3.75E-04 in the wash section. With the exception of the wash section, dispersion numbers were well above the criteria of 4.4E-04 for good separation performance. The average dispersion number of $3.75 \mathrm{E}-04$ obtained for the wash section is slightly below this criterion, indicating a potential difficulty of phase separation in the wash section of the flowsheet. It should be noted that there are inherent inaccuracies in the measurement of the break time when determining the dispersion numbers. The point at which the phases have completely separated is subject to interpretation by the experimenter. In measuring the break time for the wash section, very small aqueous droplets were observed descending through the organic phase for a considerable time after the interface returned to the original position. The end point of the separation of the phases was defined as the point when these aqueous droplets could no longer be observed. As a result, the calculated dispersion number for the wash section is conservative.

Table 5. Dispersion number measurements.

\begin{tabular}{ccccc}
\hline Test Condition & $\begin{array}{c}\text { Dispersion Height } \\
(\mathrm{ft})\end{array}$ & $\begin{array}{c}\text { Separation Time } \\
(\mathrm{s})\end{array}$ & Temperature $\left({ }^{\circ} \mathrm{C}\right)$ & $\begin{array}{c}\text { Dispersion } \\
\text { Number }\end{array}$ \\
\hline Extraction 1 & 0.509 & 94 & --- & $1.34 \mathrm{E}-03$ \\
Extraction 2 & 0.509 & 96 & --- & $1.31 \mathrm{E}-03$ \\
Extraction 3 & 0.509 & 96 & 25.5 & $1.31 \mathrm{E}-03$ \\
Scrub 1 & 0.243 & 142 & --- & $6.12 \mathrm{E}-04$ \\
Scrub 2 & 0.243 & 147 & 26.9 & $5.91 \mathrm{E}-04$ \\
Strip 1 & 0.226 & 102 & 24.2 & $8.22 \mathrm{E}-04$ \\
Strip 2 & 0.226 & 99 & 27.5 & $8.47 \mathrm{E}-04$ \\
Wash 1 & 0.207 & 239 & 29.1 & $3.35 \mathrm{E}-04$ \\
Wash 2 & 0.207 & 214 & 26.2 & $3.75 \mathrm{E}-04$ \\
Wash 3 & 0.207 & 193 & 27.1 & $4.15 \mathrm{E}-04$ \\
\hline
\end{tabular}

\section{Hydraulic Performance}

Maximum throughput as a function of rotor speed was determined for each of the flowsheet sections at the baseline O/A's of the CSSX flowsheet. The results, based upon the first observation of cross-phase entrainment and based upon $\geq 1 \%$ cross-phase entrainment, are presented in Figures 4, 5, 6, and 7 . Additionally, the maximum throughput was measured for each flowsheet section at O/A's $20 \%$ higher and lower than the baseline $\mathrm{O} / \mathrm{A}$ in order to evaluate the effects of small changes in flowrates during process operation. These results are presented in Figures 8, 9, 10 and 11. Finally, in Figures 12 and 13, the maximum throughputs obtained for the extraction and strip sections are compared to the results obtained in FY-01 at ORNL using a 5.0-cm Costner Industries Nevada Corp. (CINC) centrifugal contactor and the old solvent formulation.

\section{Extraction Section}

Maximum throughput for the extraction section ranged from $1245 \mathrm{~mL} / \mathrm{min}$ at $2800 \mathrm{rpm}$ to 1965 $\mathrm{mL} / \mathrm{min}$ at $4400 \mathrm{rpm}$ (Figure 4). In all cases of cross-phase entrainment, aqueous phase entrainment in the solvent was observed. Entrainment of the solvent in the aqueous phase was not observed. There is very little difference in maximum throughput for the two throughput evaluation criteria. When cross-phase 


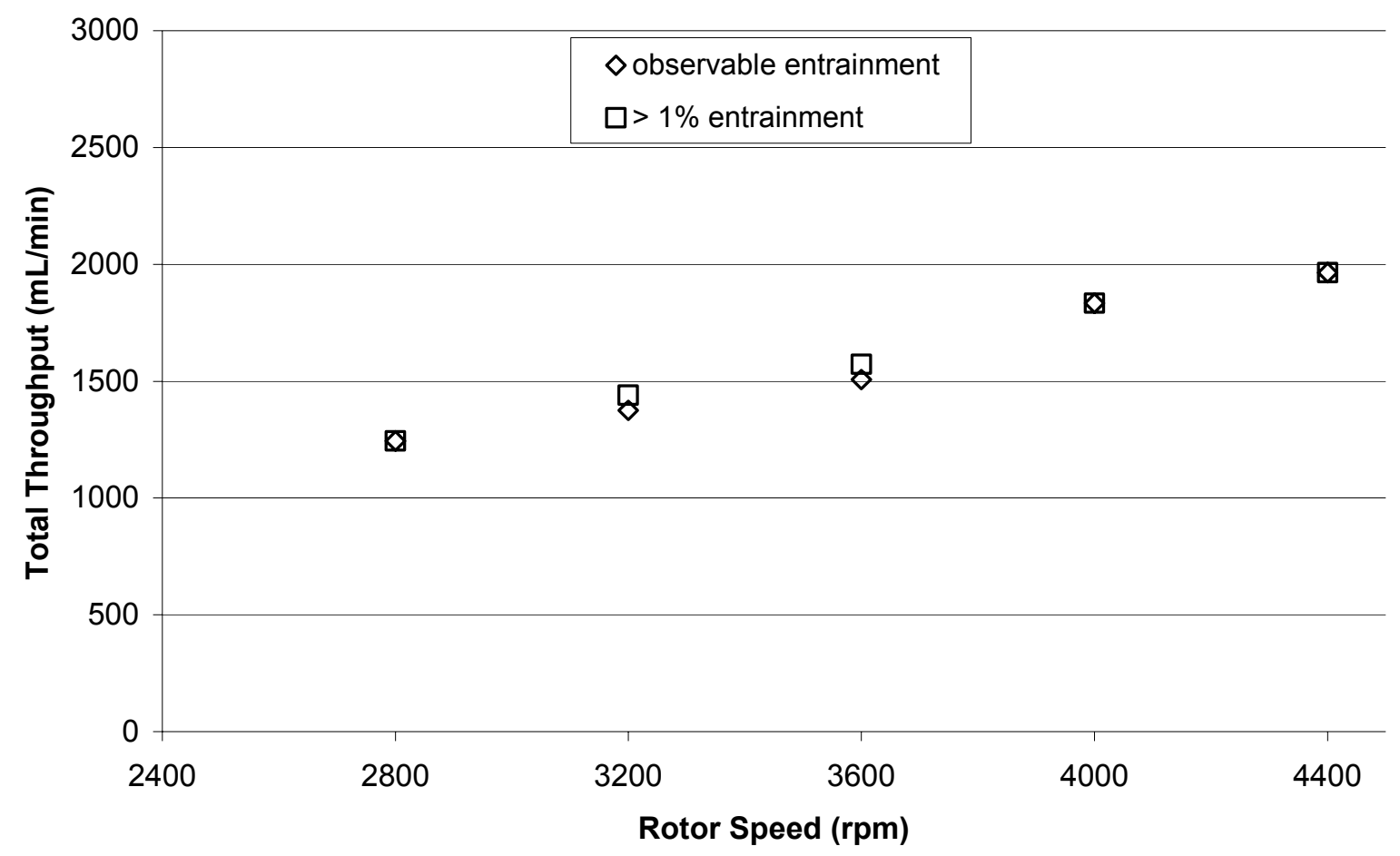

Figure 4. Extraction section maximum throughput at the baseline $\mathrm{O} / \mathrm{A}$ of 0.31 .

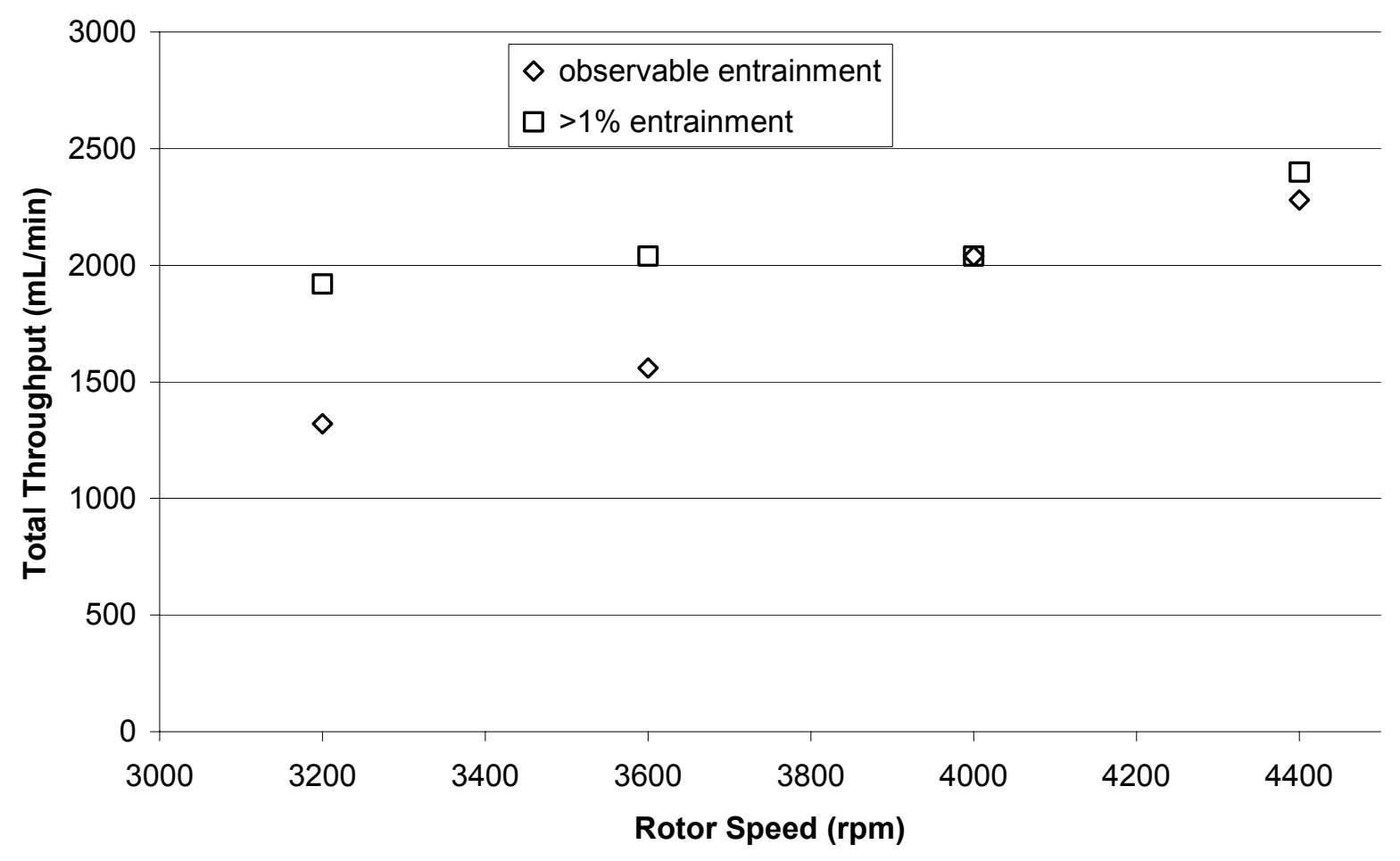

Figure 5. Scrub section maximum throughput at the baseline $\mathrm{O} / \mathrm{A}$ of 5.0. 


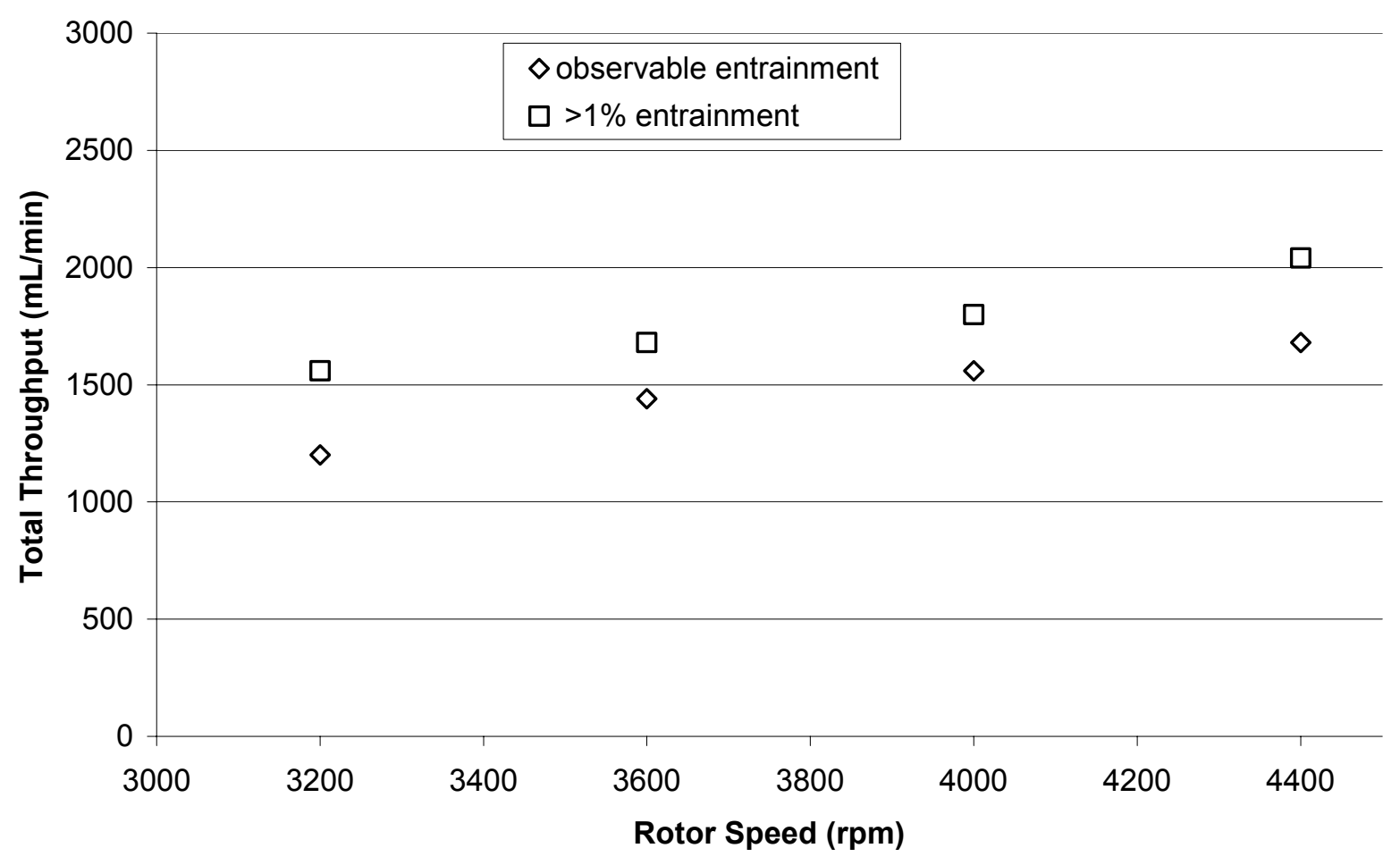

Figure 6. Strip section maximum throughput at the baseline O/A of 5.0.

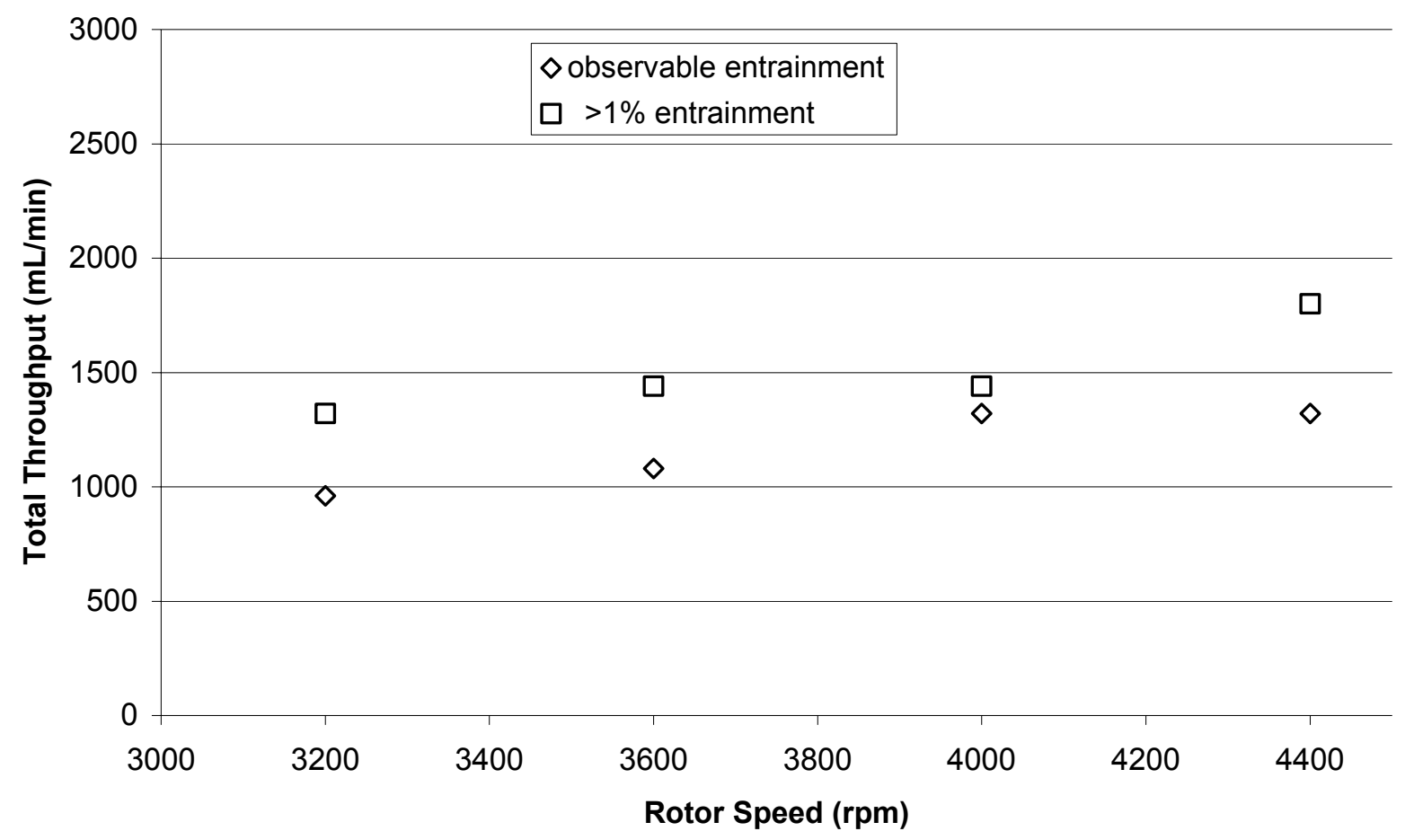

Figure 7. Wash section maximum throughput at the baseline $\mathrm{O} / \mathrm{A}$ of 5.0. 


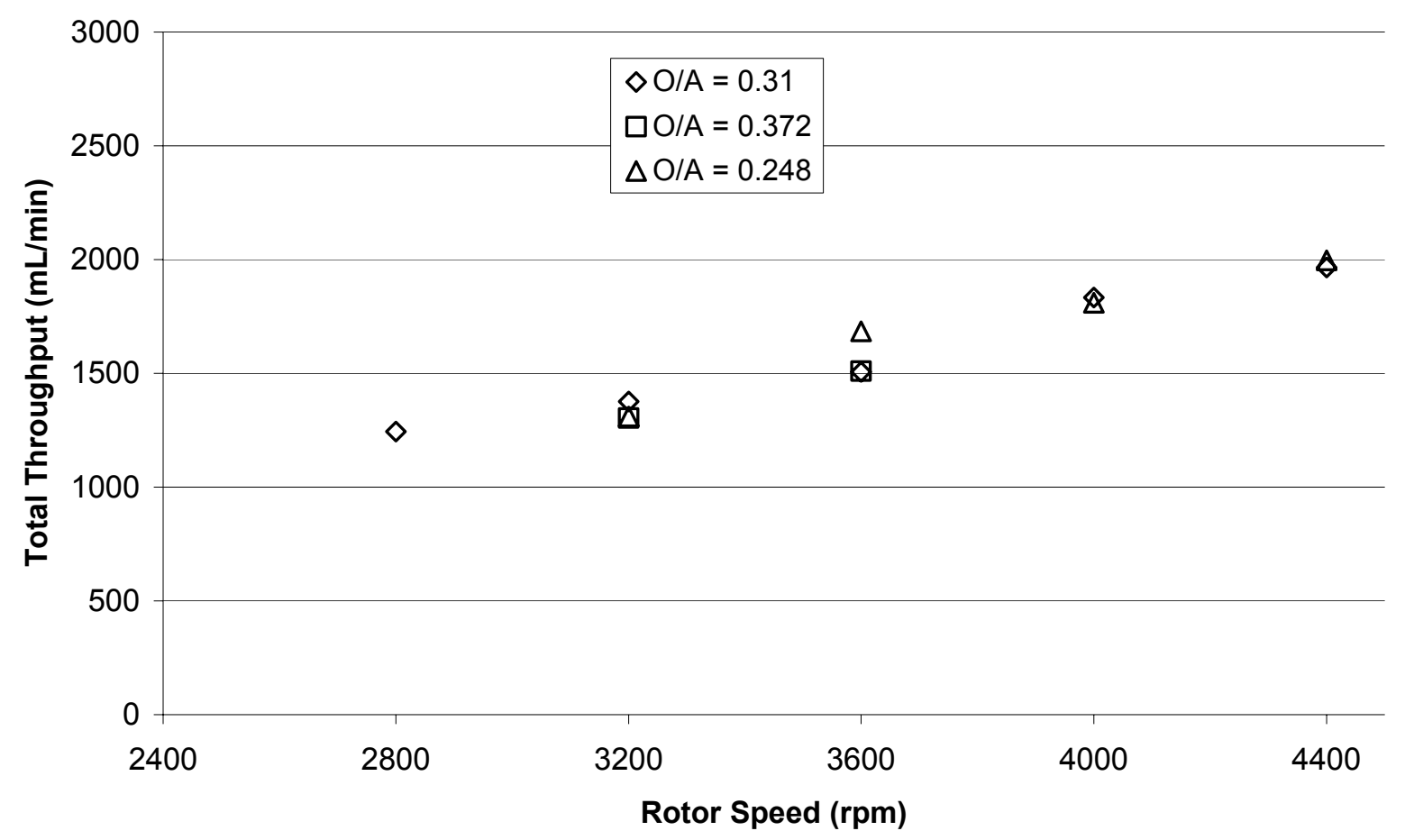

Figure 8. Extraction section maximum throughput as a function of $\mathrm{O} / \mathrm{A}$ ratio ( $\geq 1 \%$ entrainment).

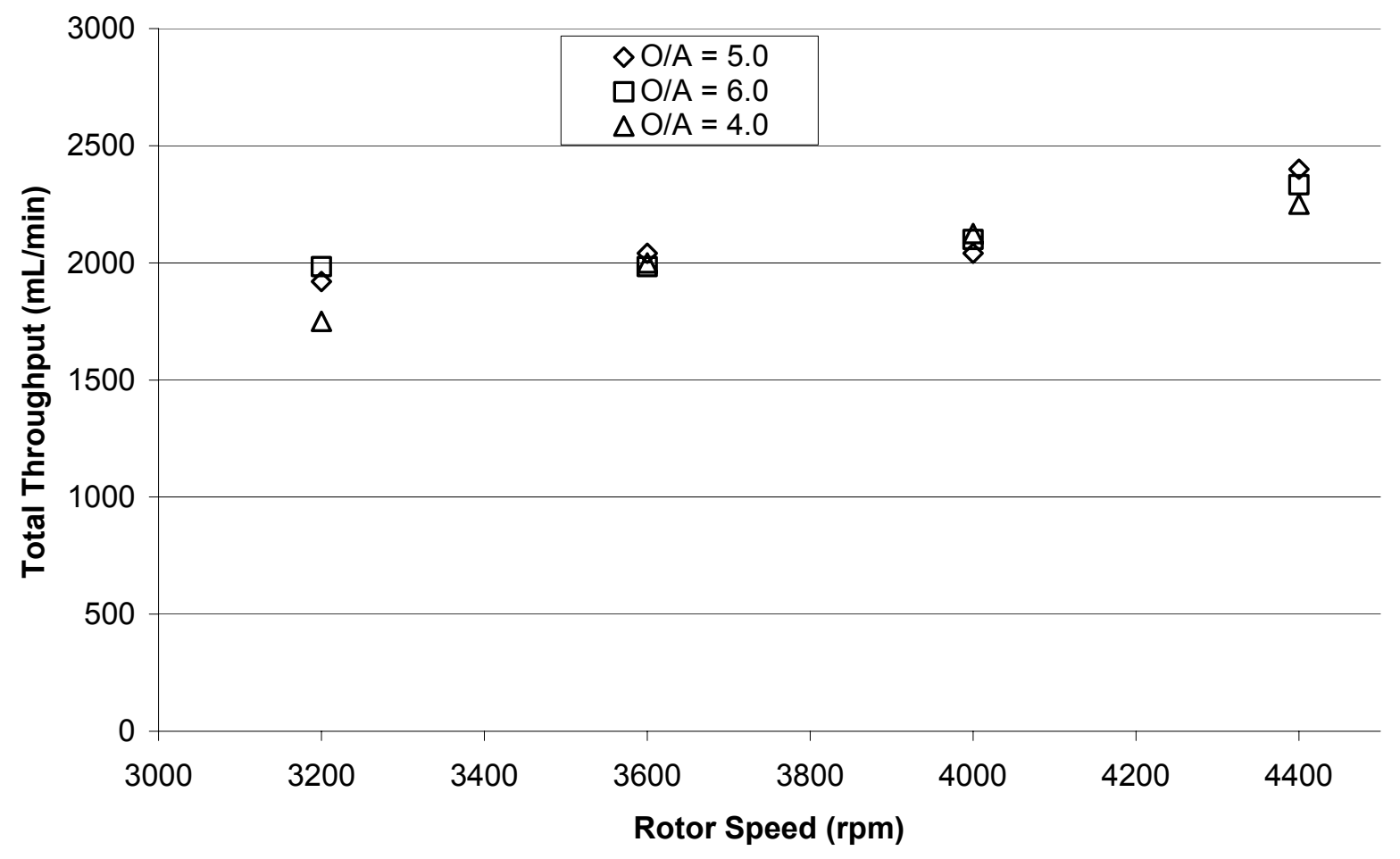

Figure 9. Scrub section maximum throughput as a function of $\mathrm{O} / \mathrm{A}$ ratio ( $\geq 1 \%$ entrainment). 


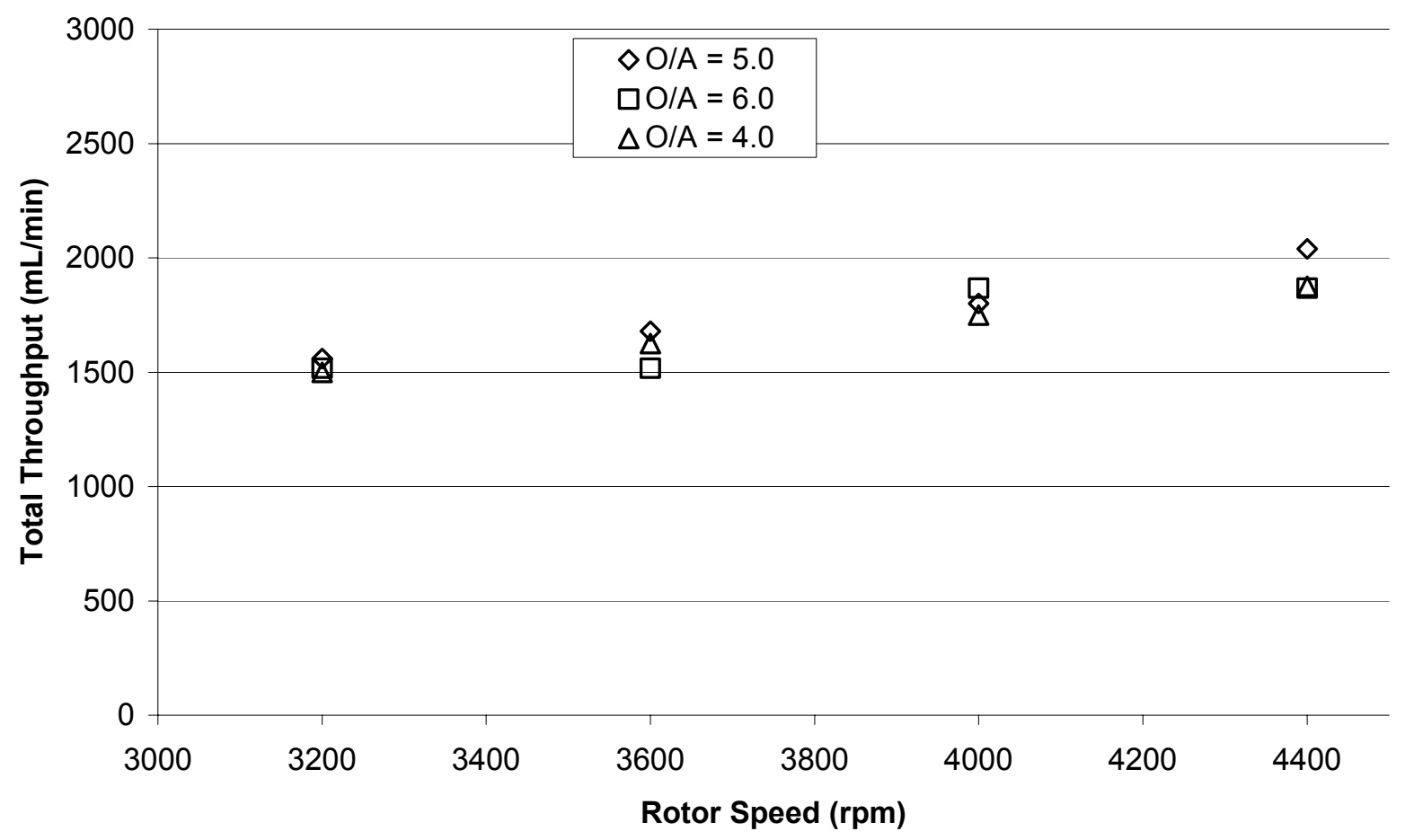

Figure 10. Strip section maximum throughput as a function of $\mathrm{O} / \mathrm{A}$ ratio ( $\geq 1 \%$ entrainment).

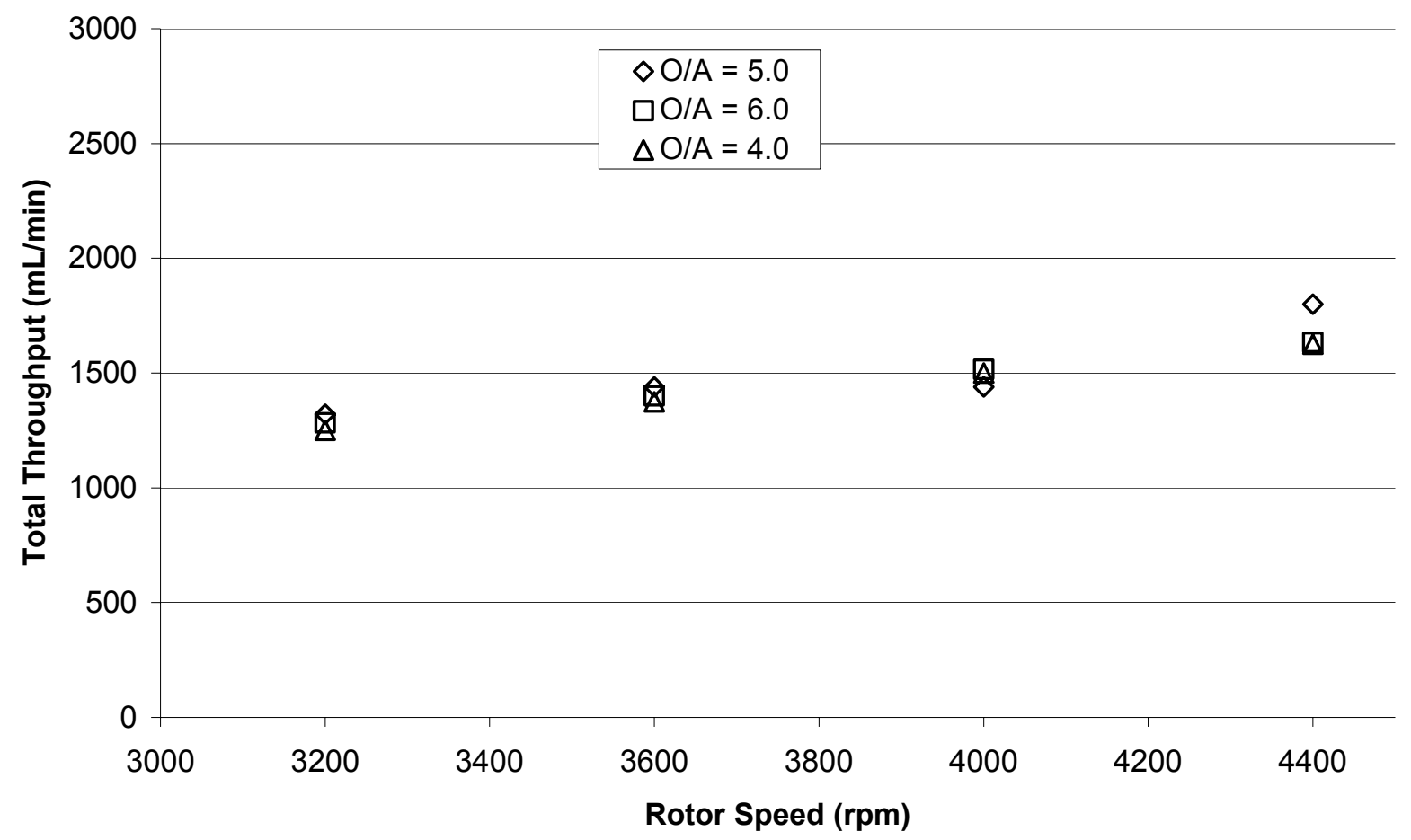

Figure 11. Wash section maximum throughput as a function of $\mathrm{O} / \mathrm{A}$ ratio ( $\geq 1 \%$ entrainment). 


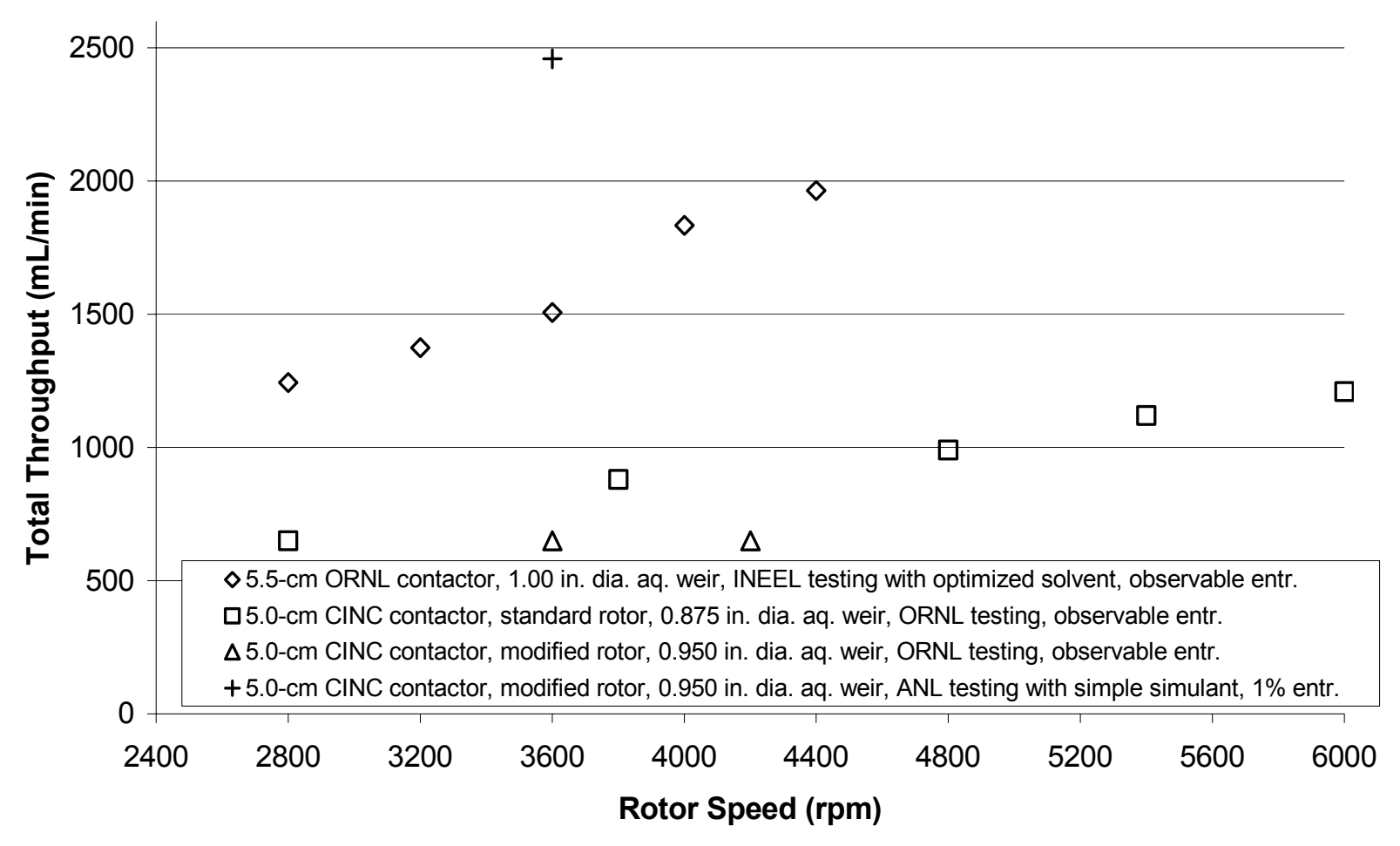

Figure 12. Comparison of extraction section maximum throughput with previous results using the nonoptimized solvent.

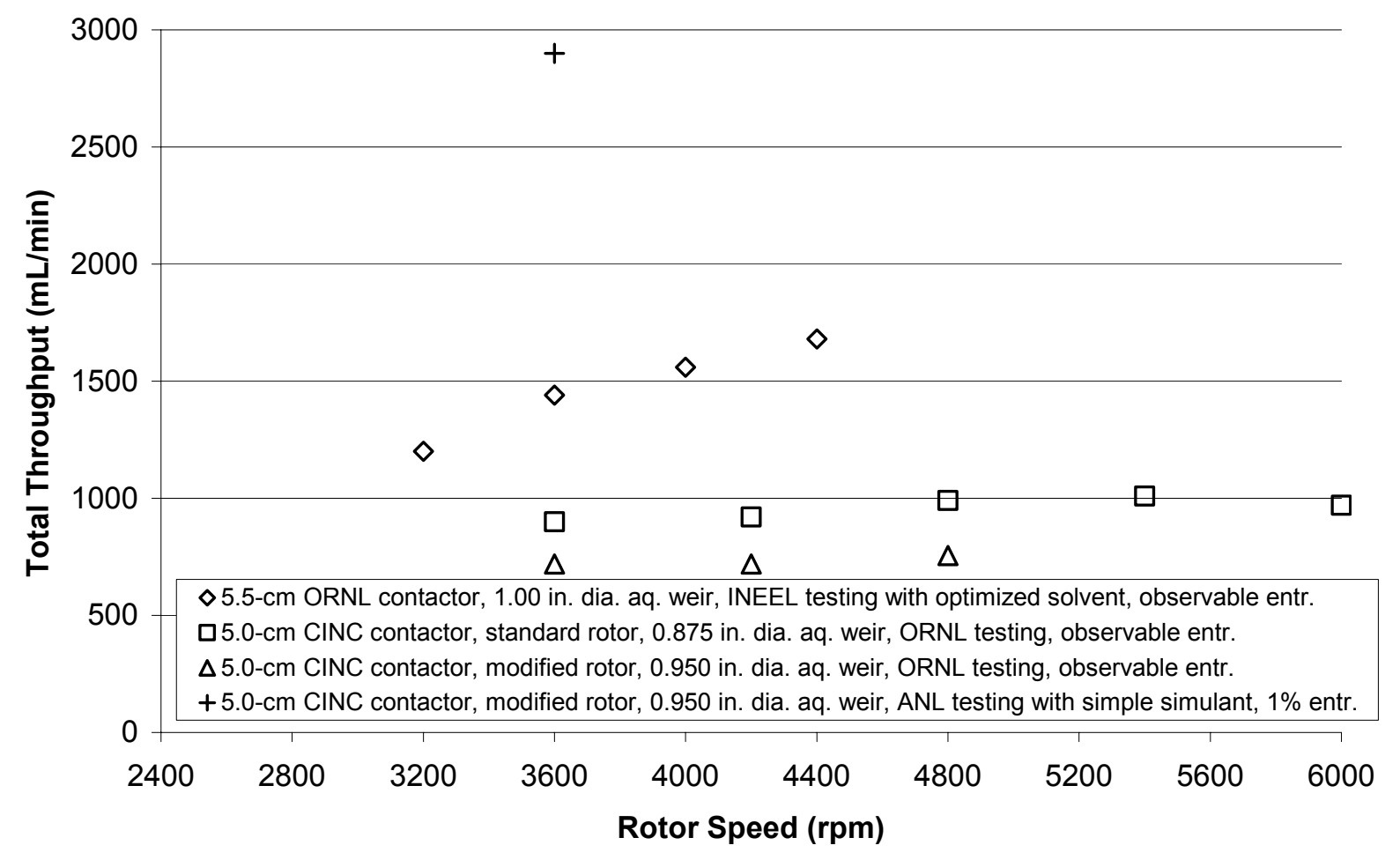

Figure 13. Comparison of strip section maximum throughput with previous results using the nonoptimized solvent. 
entrainment was first observed, it was typically in amounts $\geq 1 \%$. Maximum throughput was also measured for the extraction section at O/A's 20\% higher and lower than the baseline O/A of 0.31 (Figure 8). The maximum throughput is essentially the same at these $\mathrm{O} / \mathrm{A}$ 's indicating that small variations in extraction section process flowrates will not impact the hydraulics of the contactor.

Contactor modeling performed by Argonne National Laboratory (ANL) indicated that the total throughput of the extraction section could be increased without impacting the throughput of the strip section by increasing the radius of the more dense phase weir from $12.7 \mathrm{~mm}$ to $13.2 \mathrm{~mm}$. This change was made and hydraulic performance testing was repeated at $4000 \mathrm{rpm}$. Results were not improved with the larger diameter weir $(0.5 \%$ cross-phase entrainment at $1703 \mathrm{~mL} / \mathrm{min}$ and $6 \%$ cross-phase entrainment at $1965 \mathrm{~mL} / \mathrm{min}$ ). Additionally, some organic carryover in the aqueous phase was observed at $1703 \mathrm{~mL} / \mathrm{min}$ total throughput. The original weir was then re-installed and hydraulic testing of the scrub section was initiated.

\section{Scrub Section}

The maximum throughput for the scrub section, based on $\geq 1 \%$ entrainment, ranged from 1920 $\mathrm{mL} / \mathrm{min}$ at $3200 \mathrm{rpm}$ to $2400 \mathrm{~mL} / \mathrm{min}$ at $4400 \mathrm{rpm}$ (Figure 5). The maximum throughput for the scrub section, based on any observable entrainment, ranged from $1320 \mathrm{~mL} / \mathrm{min}$ at $3200 \mathrm{rpm}$ to $2280 \mathrm{~mL} / \mathrm{min}$ at $4400 \mathrm{rpm}$. In all cases of cross-phase entrainment, aqueous phase entrainment in the solvent was observed. Entrainment of the solvent in the aqueous phase was not observed. Maximum throughput was also measured for the scrub section at O/A's 20\% higher and lower than the baseline O/A of 5.0 (Figure 9). The maximum throughput is essentially the same at these $\mathrm{O} / \mathrm{A}$ 's indicating that small variations in scrub section process flowrates will not impact the hydraulics of the contactor.

\section{Strip Section}

The maximum throughput for the strip section, based on $\geq 1 \%$ entrainment, ranged from 1560 $\mathrm{mL} / \mathrm{min}$ at $3200 \mathrm{rpm}$ to $2040 \mathrm{~mL} / \mathrm{min}$ at $4400 \mathrm{rpm}$ (Figure 6). The maximum throughput for the strip section, based on any observable entrainment, ranged from $1200 \mathrm{~mL} / \mathrm{min}$ at $3200 \mathrm{rpm}$ to $1680 \mathrm{~mL} / \mathrm{min}$ at $4400 \mathrm{rpm}$. In all cases of cross-phase entrainment, aqueous phase entrainment in the solvent was observed. Entrainment of the solvent in the aqueous phase was typically not observed, with the exception of a few samples in which an organic film was observed on the aqueous phase. Maximum throughput was also measured for the strip section at O/A's 20\% higher and lower than the baseline O/A of 5.0 (Figure 10). The maximum throughput is essentially the same at these $\mathrm{O} / \mathrm{A}$ 's indicating that small variations in strip section process flowrates will not impact the hydraulics of the contactor.

\section{Wash Section}

The maximum throughput for the wash section, based on $\geq 1 \%$ entrainment, ranged from 1320 $\mathrm{mL} / \mathrm{min}$ at $3200 \mathrm{rpm}$ to $1800 \mathrm{~mL} / \mathrm{min}$ at $4400 \mathrm{rpm}$ (Figure 7). The maximum throughput for the wash section, based on any observable entrainment, ranged from $960 \mathrm{~mL} / \mathrm{min}$ at $3200 \mathrm{rpm}$ to $1320 \mathrm{~mL} / \mathrm{min}$ at $4400 \mathrm{rpm}$. In all cases of cross-phase entrainment, aqueous phase entrainment in the solvent was observed. Entrainment of the solvent in the aqueous phase was not observed. Maximum throughput was also measured for the wash section at O/A's 20\% higher and lower than the baseline O/A of 5.0 (Figure 11). The maximum throughput is essentially the same at these $\mathrm{O} / \mathrm{A}$ 's indicating that small variations in wash section process flowrates will not impact the hydraulics of the contactor. 


\section{Comparison of Maximum Throughput to Previous Results with Non-Optimized Solvent}

Hydraulic testing was previously performed at ORNL using a 5-cm diameter CINC contactor and the non-optimized solvent formulation (Birdwell and Anderson 2001). Additionally, limited testing was performed at ANL also using a 5-cm diameter CINC contactor and the non-optimized solvent formulation (Leonard et al. 2002). Results obtained using the 5.5-cm diameter ORNL contactor and the optimized solvent are compared to these results in Figures 12 and 13. For the extraction section, throughputs are approximately double those obtained at ORNL using the 5-cm CINC contactor and the non-optimized solvent (INEEL $-1440 \mathrm{~mL} / \mathrm{min}$ at $3600 \mathrm{rpm}$, ORNL $-720 \mathrm{~mL} / \mathrm{min}$ at $3600 \mathrm{rpm}$ ). For the testing at the INEEL and at ORNL the maximum throughputs shown were determined based on the first observation of entrainment. At ANL, a maximum throughput of $2460 \mathrm{~mL} / \mathrm{min}$ was measured at $3600 \mathrm{rpm}$ using a $5-\mathrm{cm}$ CINC contactor and the non-optimized solvent (Leonard et al. 2002). A simplified simulant was used for this testing and the criteria of $1 \%$ entrainment was used for determining throughput.

For the strip section, throughputs are also approximately double those obtained at ORNL using the 5-cm CINC contactor and the non-optimized solvent (INEEL - $1506 \mathrm{~mL} / \mathrm{min}$ at $3600 \mathrm{rpm}$, ORNL - 650 $\mathrm{mL} / \mathrm{min}$ at $3600 \mathrm{rpm}$ ). At ANL, a maximum throughput of $2900 \mathrm{~mL} / \mathrm{min}$ was measured at $3600 \mathrm{rpm}$ using a 5-cm CINC contactor and the non-optimized solvent (Leonard et al. 2002). The criteria of 1\% entrainment was again used by ANL for determining throughput.

There are several differences in the testing at the INEEL, ORNL and ANL that make a direct comparison of the results difficult. The INEEL used a slightly larger contactor, the design of the contactor used for testing at the INEEL is not identical to the CINC contactor used for the ORNL and ANL testing, and the testing performed at the INEEL was with the optimized solvent. Therefore, differences in maximum throughput can not be directly attributed to the use of the optimized solvent. What can be concluded from this testing is that the maximum throughput of the $5.5-\mathrm{cm}$ diameter ORNL-designed contactor with the optimized solvent is reasonable for this size centrifugal contactor. This conclusion is supported by comparing the results of this testing with the maximum throughput measured for the same 5.5-cm contactor with the PUREX process solvent (for which the contactor was designed). As shown in Figure 14, the total throughput for the PUREX solvent with $0.5 \mathrm{M} \mathrm{HNO}_{3}$ at an $\mathrm{O} / \mathrm{A}$ of 0.1 ranged from $500 \mathrm{~mL} / \mathrm{min}$ at $1100 \mathrm{rpm}$ to $2500 \mathrm{~mL} / \mathrm{min}$ at $4100 \mathrm{rpm}$. The total throughput for the PUREX solvent with

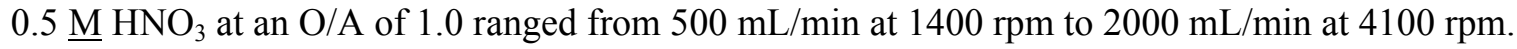

\section{Solvent Density Change During Testing}

Previous hydraulic testing at ORNL resulted in a density increase in the solvent from 822.7 to 925.6 $\mathrm{g} / \mathrm{L}$ at $25^{\circ} \mathrm{C}$ (Leonard et al. 2002). The density increase was likely a result of evaporation of the most volatile solvent component, Isopar ${ }^{\circledR}$ L. As a result, the density of the CSSX solvent was closely monitored during testing to ensure the hydraulic performance results would not be affected by a change in density. The change in density of the solvent during INEEL testing is summarized in Table 6 . Density changes were minimal, increasing by only $0.33 \%$ from the measurement of the density at ORNL until completion of the hydraulic performance tests. This minimal change in solvent density is attributed to the fact that the ORNL-designed contactor does not heat up the solvent significantly during operation. During operation, the solvent remained approximately at ambient temperature. Additionally, the solvent was stored and processed using only Teflon ${ }^{\circledR}$ bottles to prevent any potential solvent losses through the storage bottle and the bottle was kept closed when testing was not in progress. 


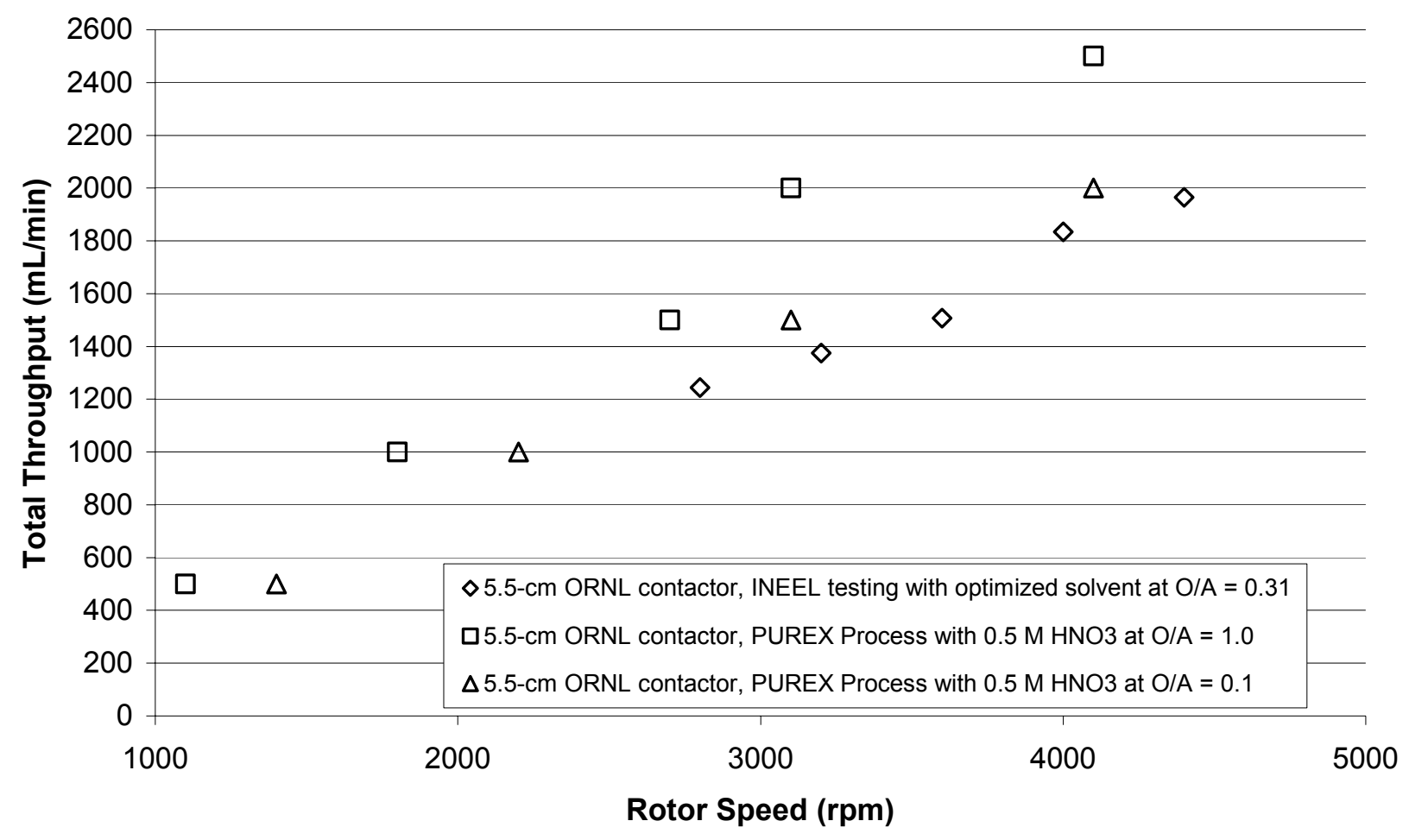

Figure 14. Comparison of maximum throughput in the extraction section with previous results obtained for the PUREX Process.

Table 6. Solvent density measurements during testing.

\begin{tabular}{|c|c|c|}
\hline \multirow[b]{2}{*}{ Time of Measurement } & \multicolumn{2}{|c|}{$\begin{array}{c}\text { Approximate } \\
\text { Cumulative Operating }\end{array}$} \\
\hline & Time (hours) & Density $(\mathrm{g} / \mathrm{mL})$ \\
\hline Prior to shipment to INEEL as measured by ORNL & --- & 0.8518 \\
\hline Two weeks after receipt as measured by INEEL & --- & 0.8524 \\
\hline At completion of hydraulic testing of the extraction section & 20 & 0.8533 \\
\hline At completion of hydraulic testing of the scrub section & 35 & 0.8536 \\
\hline At completion of hydraulic testing of the strip section & 50 & 0.8541 \\
\hline At completion of hydraulic testing of the wash section & 65 & 0.8546 \\
\hline
\end{tabular}

\section{Mass Transfer Efficiency}

Once the maximum throughputs were determined for each of the flowsheet sections, mass transfer efficiencies were measured at flowrates corresponding to $75 \%$ and $37.5 \%$ of the maximum throughput in the extraction section. Efficiencies were measured for the extraction and strip sections of the flowsheet. The results of this testing are summarized in Table 7. 
Table 7. Mass transfer efficiencies in 5.5-cm diameter contactor operating at $3600 \mathrm{rpm}$.

\begin{tabular}{|c|c|c|c|c|c|c|c|c|}
\hline \multirow[b]{2}{*}{$\begin{array}{l}\text { Flowsheet Section } \\
\text { (operation time) }\end{array}$} & \multirow{2}{*}{$\begin{array}{c}\text { Total } \\
\text { Throughput } \\
\text { (mL/min) }\end{array}$} & \multicolumn{3}{|c|}{ Level in } & \multicolumn{2}{|c|}{$\mathrm{D}_{\mathrm{Cs}}$} & \multicolumn{2}{|c|}{ Mass Balance (\%) } \\
\hline & & $\begin{array}{c}\text { Efficiency } \\
(\%)\end{array}$ & $\begin{array}{l}\text { Mixing Zone } \\
\quad(\mathrm{mm})^{1}\end{array}$ & $\begin{array}{l}\text { Residence } \\
\text { Time (s) }\end{array}$ & $\begin{array}{l}\text { Before } \\
\text { Equil. }\end{array}$ & $\begin{array}{l}\text { After } \\
\text { Equil. }\end{array}$ & $\begin{array}{l}\text { Before } \\
\text { Equil. }\end{array}$ & $\begin{array}{l}\text { After } \\
\text { Equil. }\end{array}$ \\
\hline Extraction (2.5 min.) & 1,130 & 73.5 & 31 & 1.8 & 4.8 & 13.8 & 105.6 & 105.4 \\
\hline Extraction (5 min.) & 1,130 & 72.0 & 31 & 1.8 & 4.7 & 14.8 & 106.8 & 106.0 \\
\hline Extraction ( 3 min.) & 565 & 74.2 & --- & --- & 4.8 & 13.4 & 111.1 & 109.7 \\
\hline Extraction (6 min.) & 565 & 74.4 & --- & --- & 4.9 & 13.8 & 110.9 & 112.1 \\
\hline Strip (2.5 min.) & 321 & 40.2 & 13 & 2.7 & 0.65 & 0.14 & 92.0 & 93.9 \\
\hline Strip (5 min.) & 321 & 46.5 & 13 & 2.7 & 0.51 & 0.13 & 96.3 & 97.0 \\
\hline Strip (3 min.) & 161 & 36.5 & 2 & 0.8 & 0.65 & 0.11 & 100.2 & 100.2 \\
\hline Strip (5 min.) & 161 & 36.4 & 2 & 0.8 & 0.66 & 0.11 & 92.4 & 99.1 \\
\hline
\end{tabular}

${ }^{1}$ As measured in subsequent testing with 5.5 -cm contactor in Plexiglas ${ }^{(B)}$ housing under the same operating conditions.

\section{Extraction Section}

Mass transfer efficiencies under extraction section conditions ranged from $72.0 \%$ to $73.5 \%$ at $75 \%$ of the maximum throughput of the contactor and from $74.2 \%$ to $74.4 \%$ at $37.5 \%$ of the maximum throughput of the contactor. Cesium distribution coefficients were determined based on the cesium concentrations in the effluent streams before and after re-equilibration. Before re-equilibration, the distribution coefficient for cesium ranged from 4.7 to 4.9 and after re-equilibration ranged from 13.4 to 14.8. Mass balances for each set of operating conditions were reasonable (105\% to1 $12 \%)$ and results were consistent for the various sample times and flowrates, indicating sample contamination or analytical error was likely not the cause for the low extraction efficiencies.

\section{Strip Section}

Mass transfer efficiencies under strip section conditions ranged from $40.2 \%$ to $46.5 \%$ at a throughput corresponding to $75 \%$ of the maximum throughput in the extraction section $(321 \mathrm{~mL} / \mathrm{min})$ and from $36.4 \%$ to $36.5 \%$ at a throughput corresponding to $37.5 \%$ of the maximum throughput in the extraction section $(160 \mathrm{~mL} / \mathrm{min})$. Cesium distribution coefficients were determined based on the cesium concentrations in the effluent streams before and after re-equilibration. Before re-equilibration, the distribution coefficient for cesium ranged from 0.51 to 0.66 and after re-equilibration ranged from 0.11 to 0.14. Again, mass balances for each set of operating conditions were reasonable $(92.0 \%$ to $100.2 \%)$ and results were consistent for the various sample times and flowrates, indicating sample contamination or analytical error was likely not the cause for the low stripping efficiencies.

\section{Additional Testing in Plexiglas ${ }^{\circledR}$ Contactor}

Mass transfer efficiencies for the extraction and strip sections were lower than expected. Similar testing performed at ORNL using a 5-cm CINC contactor and the non-optimized solvent yielded mass transfer efficiencies of $86 \%$ to $90 \%$ for the extraction section and $75 \%$ to $100 \%$ for the strip section (Birdwell and Anderson 2001). It should be noted that initial mass transfer efficiency test using the "asreceived" 5-cm CINC contactor resulted in inadequate efficiencies. Curved vanes in the housing bottom were replaced with straight vanes and the opening in the bottom of the rotor was enlarged from 5.076 to $9.610 \mathrm{~mm}$ to convert the rotor from fully to partially pumping. The reported mass transfer efficiencies were obtained after making these modifications.

In order to try and understand the reason for the lower than expected efficiencies, a single stage of 5.5-cm centrifugal contactor in a Plexiglas ${ }^{\circledR}$ housing was setup for testing. This contactor is identical in design to the single stage of the contactor "four-pack" previously tested except the housing is constructed of Plexiglas ${ }^{\circledR}$ which allows solution level to be measured and solution mixing to be observed. A 


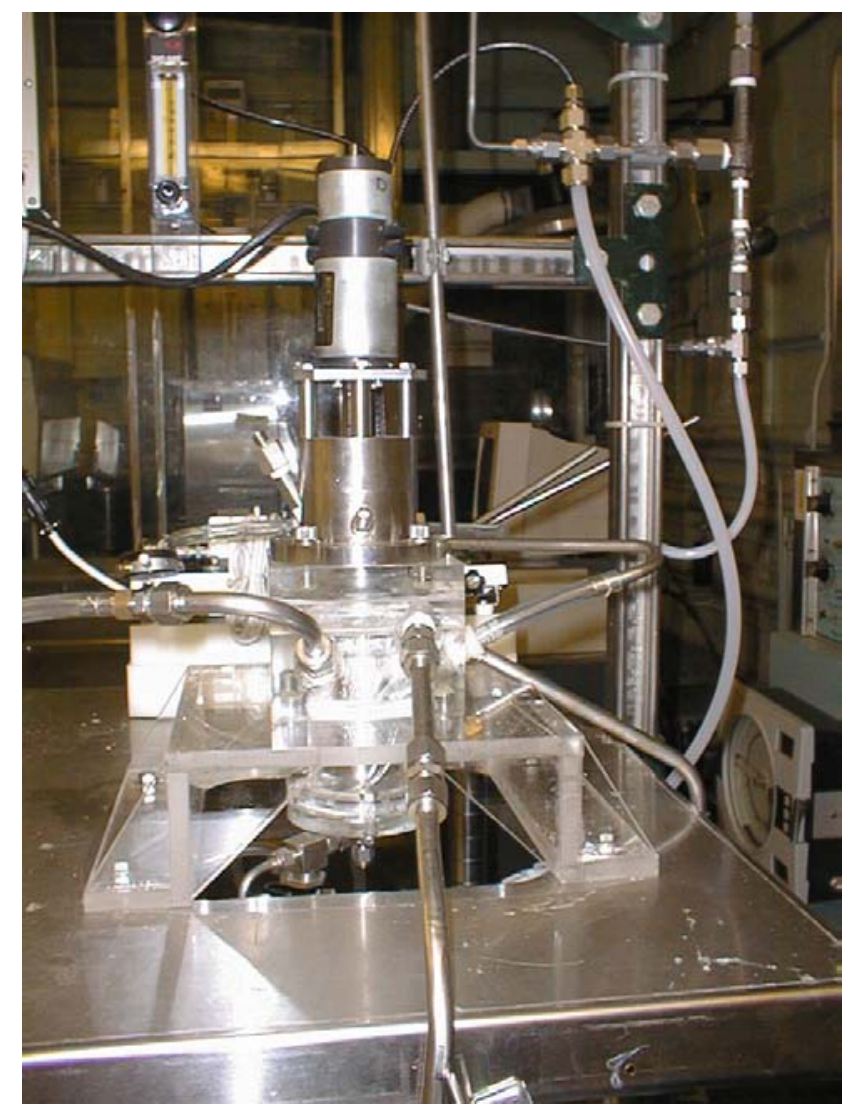

Figure 15. Single stage 5.5-cm centrifugal contactor with Plexiglas ${ }^{\circledR}$ housing.

photograph of this centrifugal contactor is shown in Figure 15. Additional mass transfer efficiency testing was performed using this Plexiglas ${ }^{\circledR}$ contactor.

Initial testing in the Plexiglas ${ }^{\circledR}$ contactor focused on measuring the liquid height in the mixing zone under each of the operating conditions of the mass transfer efficiency testing. The liquid heights, as measured from the bottom edge of the rotor, are presented in Table 7. The liquid level in the mixing zone for the extraction section efficiency testing at $75 \%$ of the maximum throughput was $31 \mathrm{~mm}(1.8 \mathrm{~s}$ residence time in the mixing zone). Increasing the rotor speed to $4000 \mathrm{rpm}$ or reducing the rotor speed to $3200 \mathrm{rpm}$ did not result in any measurable change in the liquid level (Table 8). Since these liquid levels appeared to be adequate, it was decided to repeat the mass transfer efficiency testing for the extraction section at 3200 and $4000 \mathrm{rpm}$ in order to determine if the rotor speed affects the mass transfer efficiency.

The liquid heights in the mixing zone for the strip section efficiency testing were $13 \mathrm{~mm}(2.7 \mathrm{~s}$ residence time) at the flowrates corresponding to $75 \%$ of the maximum throughput of the extraction section and $2 \mathrm{~mm}(0.8 \mathrm{~s}$ residence time $)$ at the flowrates corresponding to $37.5 \%$ of the maximum throughput of the extraction section. With theses low solution levels there was some concern that inadequate mixing was occurring and the residence time in the contactor may be too short. Increasing the total throughput by $50 \%(481 \mathrm{~mL} / \mathrm{min})$ increased the level to $30 \mathrm{~mm}(4.1 \mathrm{~s}$ residence time) and increasing the total throughput by $100 \%$ (642 $\mathrm{mL} / \mathrm{min}$ ) increased the level to $38 \mathrm{~mm}$ (Table 8$)$. Also, decreasing the rotor speed to $3200 \mathrm{rpm}$ while keeping the total throughput at $321 \mathrm{~mL} / \mathrm{min}$ increased the level to $19 \mathrm{~mm}$. Decreasing the rotor speed further to $3000 \mathrm{rpm}$ increased the level to $21 \mathrm{~mm}$ ( $4.3 \mathrm{~s}$ residence time). Based upon these results, it was decided to repeat the mass transfer efficiency testing for the strip section at the same rotor speed of $3600 \mathrm{rpm}$ but an increased total throughput $(481 \mathrm{~mL} / \mathrm{min})$, as well as at the original throughput of $321 \mathrm{~mL} / \mathrm{min}$ but a rotor speed of $3000 \mathrm{rpm}$. Under both of these conditions, the liquid level is significantly increased. 
The results from the mass transfer efficiency tests performed using the Plexiglas ${ }^{\circledR}$ contactor are given in Table 8. For the extraction section, efficiencies of $72.0 \%$ and $74.1 \%$ were obtained at 3200 and $4000 \mathrm{rpm}$, respectively. These efficiencies are comparable to the efficiency of $72.0 \%$ to $73.5 \%$ obtained previously at $3600 \mathrm{rpm}$, indicating the effect of rotor speed on efficiency is minimal between 3200 and $4000 \mathrm{rpm}$. The residence time of the solutions in the mixing zone of the contactor was the same for each of the test conditions; therefore, the effect of residence time on the efficiency in the extraction section can not be evaluated. For the strip section, the efficiency decreased slightly from $46.5 \%$ to $41.7 \%$ when the rotor speed was reduced from $3600 \mathrm{rpm}$ to $3000 \mathrm{rpm}$ at a total throughput of $321 \mathrm{~mL} / \mathrm{min}$. With this lower rotor speed, the liquid level in the mixing zone increased from $13 \mathrm{~mm}$ to $21 \mathrm{~mm}(2.7 \mathrm{~s}$ and $4.3 \mathrm{~s}$ residence time, respectively); however, the solutions may not have been mixed as well. Increasing the contactor total throughput from $321 \mathrm{~mL} / \mathrm{min}$ to $481 \mathrm{~mL} / \mathrm{min}$ at the same rotor speed of $3600 \mathrm{rpm}$ resulted in the efficiency increasing from $46.5 \%$ to $59.5 \%$. With this change in throughput, the liquid level in the mixing zone was increased from $13 \mathrm{~mm}$ to $30 \mathrm{~mm}$ and the residence time was increased from 2.7 to 4.1 seconds. At a rotor speed of 3600 , the strip section efficiency increased from $36.5 \%$ with a residence time of $0.8 \mathrm{~s}$ to $46.5 \%$ with a residence time of $2.7 \mathrm{~s}$ and to $59.5 \%$ with a residence time of $4.3 \mathrm{~s}$. With an increased residence time in the mixing zone, there is more time for mixing of the two phases to occur, resulting in an increased efficiency. Further testing would be required to verify if the stage efficiency could continue to be increased by increasing the liquid level and residence time in the contactor.

Table 8. Mass transfer efficiencies using single stage Plexiglas ${ }^{\circledR} 5.5-\mathrm{cm}$ diameter contactor.

\begin{tabular}{cccccc}
\hline Flowsheet Section & $\begin{array}{c}\text { Total Throughput } \\
(\mathrm{mL} / \mathrm{min})\end{array}$ & Rotor Speed (RPM) Efficiency $(\%)$ & $\begin{array}{c}\text { Level in Mixing } \\
\text { Zone (mm) }\end{array}$ & Residence Time (s) \\
\hline Extraction & 1,130 & 4000 & 74.1 & 31 & 1.8 \\
Extraction & 1,130 & 3200 & 72.0 & 31 & 1.8 \\
Strip & 321 & 3000 & 41.7 & 21 & 4.3 \\
Strip & 481 & 3600 & 59.5 & 30 & 4.1 \\
\hline
\end{tabular}




\section{SUMMARY AND CONCLUSIONS}

Maximum throughputs for the CSSX process with the optimized solvent were determined for a 5.5$\mathrm{cm}$ diameter ORNL-designed centrifugal contactor. Throughputs in the extraction section based on 1\% cross-phase entrainment ranged from $1245 \mathrm{~mL} / \mathrm{min}$ at $2800 \mathrm{rpm}$ to $1965 \mathrm{~mL} / \mathrm{min}$ at $4400 \mathrm{rpm}$.

Throughputs ranged from $1920 \mathrm{~mL} / \mathrm{min}$ at $3200 \mathrm{rpm}$ to $2400 \mathrm{~mL} / \mathrm{min}$ at $4400 \mathrm{rpm}$ in the scrub section, $1560 \mathrm{~mL} / \mathrm{min}$ at $3200 \mathrm{rpm}$ to $2040 \mathrm{~mL} / \mathrm{min}$ at $4400 \mathrm{rpm}$ in the strip section, and $1320 \mathrm{~mL} / \mathrm{min}$ at 3200 $\mathrm{rpm}$ to $1800 \mathrm{~mL} / \mathrm{min}$ at $4400 \mathrm{rpm}$ in the wash section. Variations in O/A ratio of $20 \%$ had no significant effect on the maximum throughput in any of the flowsheet sections. Maximum throughputs are comparable to the design throughput of the contactor, as well as with throughputs obtained previously in a 5-cm centrifugal contactor with the non-optimized CSSX solvent formulation.

Mass transfer efficiencies of a single stage of $5.5-\mathrm{cm}$ diameter centrifugal contactor have been determined for the extraction and strip sections of the flowsheet. Efficiencies were lower than the process goal of $\geq 80 \%$, ranging from 72 to $75 \%$ for the extraction section and from 36 to $47 \%$ in the strip section. Additional testing was performed using a single stage of $5.5-\mathrm{cm}$ centrifugal contactor in a Plexiglas ${ }^{\circledR}$ housing so solution levels could be monitored. For the extraction section, variation in the rotor speed from $3200 \mathrm{rpm}$ to $4000 \mathrm{rpm}$ did not have a significant effect on solution levels $(31 \mathrm{~mm})$ or mass transfer efficiency. For the strip section, increasing the throughput from $321 \mathrm{~mL} / \mathrm{min}$ to $481 \mathrm{~mL} / \mathrm{min}$ increased the level in the mixing zone from $13 \mathrm{~mm}$ to $30 \mathrm{~mm}$ and resulted in the efficiency increasing from $46.5 \%$ to $59.5 \%$.

At this point it is not fully understood why the mass transfer efficiencies are low. Efficiencies could potentially be increased by increasing the mixing intensity and/or the solution level in the mixing zone of the centrifugal contactor (residence time). This would require changes in the design of the contactor. Several methods are available to accomplish this including (1) increasing the size of the opening in the bottom of the rotor, resulting in a contactor which is partially pumping instead of fully pumping, (2) decreasing the number of vanes in the contactor, (3) increasing the vane height, or (4) adding vanes on the rotor and baffles on the housing of the contactor. For the strip section, the flowrates in the $5.5-\mathrm{cm}$ centrifugal contactor are very low as a result of the $\mathrm{O} / \mathrm{A}$ 's of the flowsheet. Increased flowrates resulted in an increase in residence time and stage efficiency. The residence time and stage efficiency could also potentially be increased through the use of a smaller size centrifugal contactor in the strip section operating with the original low flowrates.

The low efficiency results obtained stress the importance of proper design of a centrifugal contactor for use in the CSSX process. A prototype of any centrifugal contactors designed for future pilot-scale or full-scale processing should be thoroughly tested prior to implementation. 


\section{REFERENCES}

Birdwell and Anderson 2001

J. F. Birdwell and K. K. Anderson, 2001, Evaluation of 5-cm Centrifugal Contactor Hydraulic and Mass Transfer Performance for Caustic-Side Solvent Extraction of Cesium, ORNL/TM-2001/137.

Bonnesen et al. 1998

P. V. Bonnesen, L. H. Delmau, T. J. Haverlock, and B. A. Moyer, 1998, Alkaline-Side Extraction of Cesium from Savannah River Tank Waste using a Calixarene-Crown Ether Structure, ORNL/TM13704.

Klatt et al. 2002

L. N. Klatt, J. F. Birdwell, P. V. Bonnesen, L. H. Delmau, L. J. Foote, D. D. Lee, R. A. Leonard, T. G. Levitskaia, M. P. Maskarinec, and B. A. Moyer, 2002, Caustic-Side Solvent Extraction SolventComposition Recommendations, ORNL/TM-2001/258.

Leonard 1995

R. A. Leonard, 1995, "Solvent Characterization using the Dispersion Number," Sep. Sci. Technol., Vol. 30, pp. 1103-1122.

Leonard et al. 2002

R. A. Leonard, M. C. Regalbuto, S. B. Aase, H. A. Arafat, and J. R. Falkenberg, 2002, Hydraulic Performance of a 5-cm CINC Contactor for Caustic-Side Solvent Extraction, ANL-02/18.

Peterson 2000

R. A. Peterson, 2000, Preparation of Simulated Waste Solutions for Solvent Extraction Testing, WSRC-RP-2000-361. 
